\title{
Volumetric intake flow measurements of an IC engine using magnetic resonance velocimetry
}

\author{
Daniel Freudenhammer $\cdot$ Elias Baum $\cdot$ \\ Brian Peterson · Benjamin Böhm • Bernd Jung • \\ Sven Grundmann
}

Received: 13 December 2013/Revised: 2 April 2014/Accepted: 5 April 2014/Published online: 1 May 2014

(c) Springer-Verlag Berlin Heidelberg 2014

\begin{abstract}
Magnetic resonance velocimetry (MRV) measurements are performed in a 1:1 scale model of a singlecylinder optical engine to investigate the volumetric flow within the intake and cylinder geometry during flow induction. The model is a steady flow water analogue of the optical IC-engine with a fixed valve lift of $9.21 \mathrm{~mm}$ to simulate the induction flow at crank-angle $270^{\circ}$ bTDC. This setup resembles a steady flow engine test bench configuration. MRV measurements are validated with phaseaveraged particle image velocimetry (PIV) measurements performed within the symmetry plane of the optical engine. Differences in experimental operating parameters between MRV and PIV measurements are well addressed. Comparison of MRV and PIV measurements is demonstrated using normalized mean velocity component profiles and
\end{abstract}

D. Freudenhammer $(\bowtie) \cdot S$. Grundmann

Center of Smart Interfaces, Technische Universität Darmstadt, Flughafenstr. 19, 64347 Griesheim, Germany

e-mail: freudenhammer@csi.tu-darmstadt.de

E. Baum · B. Peterson

Reaktive Strömungen und Messtechnik, Technische Universität Darmstadt, Jovanka-Bontschits-Str. 2, 64287 Darmstadt,

Germany

B. Böhm

Energie- und Kraftwerkstechnik, Technische Universität Darmstadt, Jovanka-Bontschits-Str. 2, 64287 Darmstadt, Germany

B. Jung

Klinik für Radiologie, Medizin Physik, Universitätsklinikum Freiburg, Breisacher Str. 60a, 79106 Freiburg, Germany

B. Jung

Department of Radiology, University Hospital Bern, 3010 Bern, Switzerland showed excellent agreement in the upper portion of the cylinder chamber (i.e., $y \geq-20 \mathrm{~mm}$ ). MRV measurements are further used to analyze the ensemble average volumetric flow within the 3D engine domain. Measurements are used to describe the 3D overflow and underflow behavior as the annular flow enters the cylinder chamber. Flow features such as the annular jet-like flows extending into the cylinder, their influence on large-scale in-cylinder flow motion, as well as flow recirculation zones are identified in 3D space. Inlet flow velocities are analyzed around the entire valve curtain perimeter to quantify percent mass flow rate entering the cylinder. Recirculation zones associated with the underflow are shown to reduce local mass flow rates up to $50 \%$. Recirculation zones are further analyzed in $3 \mathrm{D}$ space within the intake manifold and cylinder chamber. It is suggested that such recirculation zones can have large implications on cylinder charge filling and variations of the in-cylinder flow pattern. MRV is revealed to be an important diagnostic tool used to understand the volumetric induction flow within engine geometries and is potentially suited to evaluate flow changes due to intake geometry modifications.

\section{Introduction}

The engine in-cylinder turbulent flow has long been recognized as one of the key parameters influencing engine performance in spark-ignition (SI) engines. During the intake stroke, a large-scale flow motion is created, typically regarded as tumble or swirl (Hill and Zhang 1994) and includes high levels of turbulence (Tabaczynski 1976). The large-scale motion is primarily defined by the geometry of the intake system (manifold, inlet port, valve(s)) and cylinder geometry (Heywood 1988). Kinetic energy is stored 
into the large-scale motion and is regarded to dissipate into smaller-scale turbulent flow structures during the end of compression, which enables a faster burning rate for optimal combustion. Additionally, the three-dimensional (3D) flow over the intake valves and valve curtain (i.e., annular area between valve seat and valve head) defines charge filling and has large implications on volumetric efficiency. Proper control and optimization of the intake flow into the cylinder can provide greater improvement in fuel savings and engine-out emissions.

Oftentimes, characterization of the intake flow into the cylinder is performed within a steady flow engine test bench with equivalent engine geometry and fixed valve positions. Such is common practice to characterize the swirl or tumble generating capability of the intake ports using windmill-, vane-, or impulse-type torque meters (Fitzgeorge and Allison 1962; Heim and Ghandhi 2011). Further details of the flow within the regions of the inlet port and valve curtain are challenging due to the limited access for velocity measurements. To resolve flows in such regions, laser Doppler anemometry (LDA) is typically employed, which often utilize an acrylic plastic replica of the engine with liquid working fluid (e.g., oil of turpentine and tetralin) for refractive index matching (Tindal et al. 1988; Cheung et al. 1990; Chen et al. 1995; Mahmood et al. 1996; Nadarajah et al. 1998), but has also been employed with air as the working fluid (Bicen et al. 1985). Hot-wire anemometry is another measurement technique that has provided air flow velocities in the valve curtain region for fixed valve lifts within steady flow test benches (Pajković and Petrović 2008; Khalighi et al. 1986) and within modified working engines under motored operation (El Tahry et al. 1987). Hot-wire anemometry, however, is often denoted as more obtrusive due to flow interference from the hot-wire probe (Cheung et al. 1990).

Previous investigations have provided noteworthy flow measurements that have resolved global flow parameters (swirl- or tumble ratio (Fitzgeorge and Allison 1962)), evaluated local inlet flow details with respect to inlet port geometries and fixed valve positions (Bicen et al. 1985; Khalighi et al. 1986; El Tahry et al. 1987; Tindal et al. 1988; Cheung et al. 1990; Chen et al. 1995; Mahmood et al. 1996; Pajković and Petrović 2008), influence on the resulting in-cylinder flow (Cheung et al. 1990; Chen et al. 1995; Mahmood et al. 1996; Bensler et al. 1998; Nadarajah et al. 1998; Fan et al. 1999), as well as identify potential causes for cyclic variability (Justham et al. 2006). Such measurements reveal that the inlet flow is highly dependent on the inlet and in-cylinder geometry, but have also revealed inlet flow orientations that can enhance the tumble or swirl motion. Previous measurements, however, have been limited to point-wise or planar velocimetry measurements, and volumetric flow field measurements are recognized as important especially to quantify the annular inlet flow into the cylinder (Baum et al. 2013). Furthermore, as 3D computational flow models are an attractive tool for engine development, there is a need for experimental data that quantify the volumetric annular flow within the inlet port, over the intake valves, and into the cylinder chamber.

Magnetic resonance velocimetry (MRV) is an advanced diagnostic tool based on magnetic resonance imaging (MRI) introduced in 1973 (Haacke et al. 1999). MRV can be applied in any magnetic resonance (MR) scanner used for clinical research using special sequences. It is a versatile experimental method, capable of resolving ensemble mean velocities in volumetric domain (Elkins and Alley 2007), turbulent flow quantities (Elkins et al. 2008), and local species concentrations (Benson et al. 2010). The time for data acquisition of volumes of approx. $400 \mathrm{~mm}$ in diameter and $300 \mathrm{~mm}$ in length is less than an hour, and rigorous data post-processing is not required. Since optical access is not needed for data acquisition, the use of MRV is convenient in highly complex geometries for which traditional velocimetry techniques are often limited.

The focus of this work is to apply MRV measurements within an engine-equivalent Polyamide model with 1:1 scale geometry of a single-cylinder optical engine (Baum et al. 2014). MRV measurements in this work are utilized as a steady flow engine test bench analysis, which uses water with a Gadolinium-based contrast agent as a working fluid. MRV data are validated with phase-averaged particle image velocimetry (PIV) measurements performed within the tumble plane within the central cylinder axis. Differences of experimental operating parameters between the PIV and MRV measurements are well addressed. Flow field images are first analyzed within selected tumble, cross-tumble, and swirl planes to describe the 3D nature of the inlet flow entering the cylinder chamber. Volumetric flow information is then analyzed within the valve curtain and intake manifold regions. Recirculation zones in 3D space are identified in the inlet port and around the periphery of the valve curtain. The volumetric flow images clearly reveal the capabilities of MRV to better understand the 3D flow during the induction event within realistic engine geometries.

\section{Experimental setup}

\subsection{Optical engine and PIV measurements}

The engine under investigation is a single-cylinder directinjection spark-ignition (DISI) optical engine (Baum et al. 2014). It features a twin-cam, overhead-valve pentroof cylinder head with dual-port intake system designed to 
provide a tumble flow motion within the combustion chamber. The bore and stroke of this engine are both $86 \mathrm{~mm}$ with a geometric compression ratio of 8.5. Optical access into the DISI combustion chamber is provided by a $55 \mathrm{~mm}$ height quartz-glass liner (20 $\mathrm{mm}$ thickness), an 8-mm window extension into the pentroof, and a Bowditch-piston with flat quartz-glass piston-crown window (75 mm diameter). Additionally, optical access is granted into the straight piping of the intake manifold by a DN50 (56.3 mm inner dia., $70 \mathrm{~mm}$ length) fused-silica cylinder. An overview of the important engine parameters are given in Table 1.

For the verification of the MRV measurements, two PIV experiments were carried out within the motored optical engine operated at $800 \mathrm{RPM}$. The first measured the 2D flow field within the straight pipe of the intake manifold located approx. $7 D$ upstream the intake valves ( $D=56.3 \mathrm{~mm}$, red line Fig. 2) to estimate the bulk velocity in front of the bifurcation during the intake stroke. The second set of PIV measurements was performed within the combustion chamber to quantify the 2D2C (twodimensional, two-component) vector flow field within the central axis of the engine cylinder (i.e., tumble plane, $z=0 \mathrm{~mm}$ ) (Baum et al. 2014). Both sets of PIV measurements were performed separately at crank-angle (CA) $270^{\circ}$ before top-dead-center (bTDC).

For both PIV measurement sets, a frequency-doubled Nd:YAG dual-cavity laser (Edgewave INNOSLAB IS16 II-E, $532 \mathrm{~nm}, 10 \mathrm{~mJ}$ ) and a 12 bit CMOS camera (Phantom V.711, $1,280 \times 800$ pixels, double-frame exposure) were used. The measurement system was synchronized to the engine by an optical crank-angle encoder (AVL) and a programmable timing controller (LaVision, HS-Controller V2). For the measurement in the intake manifold, 78 phaselocked velocity images at $270^{\circ}$ bTDC were acquired at 13.3 Hz. The statistic of the velocity data in the tumble plane is based on 2,700 phase-locked velocity images at

Table 1 Engine-operating parameters

\begin{tabular}{lll}
\hline RPM & 800 & $\mathrm{~min}^{-1}$ \\
Avg. Press. intake & 0.95 & $\mathrm{bar}$ \\
Avg. Press. exhaust & 1.00 & $\mathrm{bar}$ \\
Intake temp. & 296 & $\mathrm{~K}$ \\
Compression ratio & 8.5 & - \\
Intake valve diameter & 33 & $\mathrm{~mm}$ \\
Intake valve open (IVO) & 325 & ${ }^{\circ} \mathrm{aTDC}$ \\
Intake valve close (IVC) & 125 & ${ }^{\circ} \mathrm{bTDC}$ \\
Exhaust valve open (EVO) & 105 & ${ }^{\circ} \mathrm{aTDC}$ \\
Exhaust valve close (EVC) & 345 & ${ }^{\circ} \mathrm{bTDC}$ \\
Maximum valve lift (IV) & 9.5 & $\mathrm{~mm}$ \\
Crank-angle of max. valve lift & 250 & ${ }^{\circ} \mathrm{bTDC}$ \\
\hline
\end{tabular}

$270^{\circ}$ bTDC. An overview of the in-cylinder PIV measurements and engine-operating conditions can be found in Baum et al. (2014).

A commercial software program (LaVision, DaVis 8.1.2) was used for processing all PIV images. Images of a spatially defined target (LaVision, Type 7), placed within the quartz-glass intake manifold and quartz-glass engine cylinder, were used for camera calibration. Mie scattering images were cross-correlated with decreasing window size multi-pass iterations $(96 \times 96$ to $32 \times 32)$ with $75 \%$ window overlap, which provided a spatial resolution of $1.1 \mathrm{~mm}$ within the intake manifold and $1.8 \mathrm{~mm}$ within the engine. The spatial resolution is based on the final interrogation window size (i.e., $32 \times 32$ ). Vector post-processing was performed for all PIV images, which utilized a peak ratio factor of 1.3 and a median filter operation to remove spurious vectors (Westerweel 1994). A $3 \times 3$ Gaussian smoothing filter was applied to the vector field to remove noise at spatial scales near the resolution limit of the PIV measurements (Fajardo and Sick 2009).

\subsection{Flow apparatus and MR scanner}

The experiments were conducted using the flow supply system described in detail in Grundmann et al. (2012). It provides a flow rate of up to $70 \mathrm{~L} / \mathrm{min}$ using a $0.55 \mathrm{~kW}$ rotary-pump (Grundfos, CME3-2). De-ionized water with a Gadolinium-based contrast agent (Magnevist, Bayer Schering, Germany) with a concentration of $1.08 \mathrm{mmol} / \mathrm{L}$ was used as working fluid. The contrast agent is added to reduce the T1-relaxation time after the electromagnetic excitation of the spins of the hydrogen nuclei for the transmission of a measurable signal. This quantum mechanical effect allows conducting such measurements in a reasonable time and is not to be confused with the seeding necessary for optical measurements.

The flow supply system contains a $70-\mathrm{L}$ water tank in which the water can be heated to $50^{\circ} \mathrm{C}$ by using a $2-\mathrm{kW}$ heater coil to increase the Reynolds number of the flow in the model. The pressure and temperature of the flow is measured downstream of the pump with a pressure sensor (Jumo Midas, 401001) and a Pt100 temperature sensor, respectively. The flow rate is monitored by a paddle-wheel flow meter (Bürkert, 8030DN15). All parameters are monitored and controlled using a purpose-made LabView program. The flow apparatus is situated in the control room next to the MR scanner room. Figure 1 provides a schematic overview of the MRV setup.

The MRV experiments were carried out in cooperation with the Department of Radiology at the University Medical Center Freiburg. A Siemens MAGNETOM MR Scanner (Siemens Magnetom Trio) with a 3 Tesla main magnetic field was used for the 3D flow measurements. A 3D phase- 


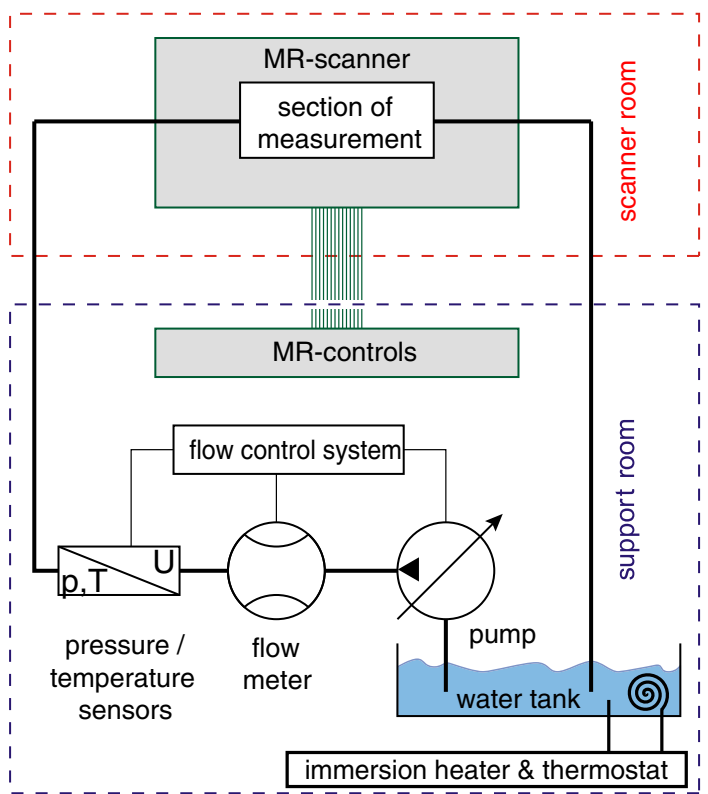

Fig. 1 Schematic illustration of the experimental setup with flow supply system and MR scanner according to Grundmann et al. (2012)

contrast imaging (PC) sequence, sensitive to fluid motion, was used for data acquisition. The MR sequences capable of measuring fluid flows originate from medical applications to visualize blood flow inside vessels (Boesiger and Maler 1992; O'Donnell 1985) and have been adapted for measuring technical flows of engineering sciences.

\subsection{MRV model and manufacturing}

A 1:1 scale model of the DISI engine (referred to as $M R V$ model) was produced from Polyamide by laser-sintering (EOS, Formiga P100) for the MRV measurements (Fig. 2). The working fluid enters the MRV model through a diffuser, with a total length of $670 \mathrm{~mm}$, which expands the cross section from the supply hoses $(25.4 \mathrm{~mm})$ to the diameter of the intake pipe $(56.3 \mathrm{~mm})$. The red line in Fig. 2 indicates the position where the unmodified engine geometry begins within the MRV model. The flow enters the cylinder downstream of the bifurcation through two separate intake ports. The lift of the intake valves is fixed to $9.21 \mathrm{~mm}$ with respect to the closed position. This position corresponds to a CA of $270^{\circ} \mathrm{bTDC}$. The cylinder rotation axis of the engine is tilted at an angle of $\alpha=63^{\circ}$ toward the diffuser rotation axis (Fig. 2 bottom right). The intake valves are tilted at an angle of $\beta=23^{\circ}$ toward the cylinder rotation axis (Fig. 3). The piston does not exist within the MRV model; the fluid exits through the bottom of the cylinder chamber into a plenum and is then recirculated back to the flow supply system.

The manufacturing of the MRV model using rapid prototyping is a quick and cost-efficient method helping to study variances in the ensemble average volumetric flow motion with respect to engine and intake geometry modifications. Although the valve position was fixed for this investigation, the valve lift can be adjusted to measure the volumetric flow at other CA positions and is the focus of future investigations.

\subsection{MRV data acquisition and measurement procedure}

The working principle of all MR sequences is based on the nuclear magnetic resonance (NMR) quantum mechanical phenomenon: In the existence of a strong magnetic field, subatomic nuclides precess at a resonance frequency, namely the Larmor-frequency $\omega_{\mathrm{L}}$ (Haacke et al. 1999; Elkins and Alley 2007). The axis of the precession motion is the direction of the main magnetic field. A resulting magnetization of the atomic nucleus appears in the case of an odd number of protons and neutrons, as in the case of hydrogen.

The Larmor-frequency $\omega_{\mathrm{L}}$ is a function of the materialdependent gyromagnetic ratio $\gamma$ and the local magnetic field strength $B$, which is composed of the main magnetic field $B_{0}$ and superimposed local magnetic field gradients $\boldsymbol{G}(t)$. These field gradients can be created along arbitrary axes $\boldsymbol{r}(t)$ through gradient coil systems that are an inherent part of clinical MR scanners.
Fig. 2 Sectional top- and sideview of the MRV model with diffuser and bifurcation. The $R e$-number was calculated using the cross-section in the diffuser marked with the red dotted line

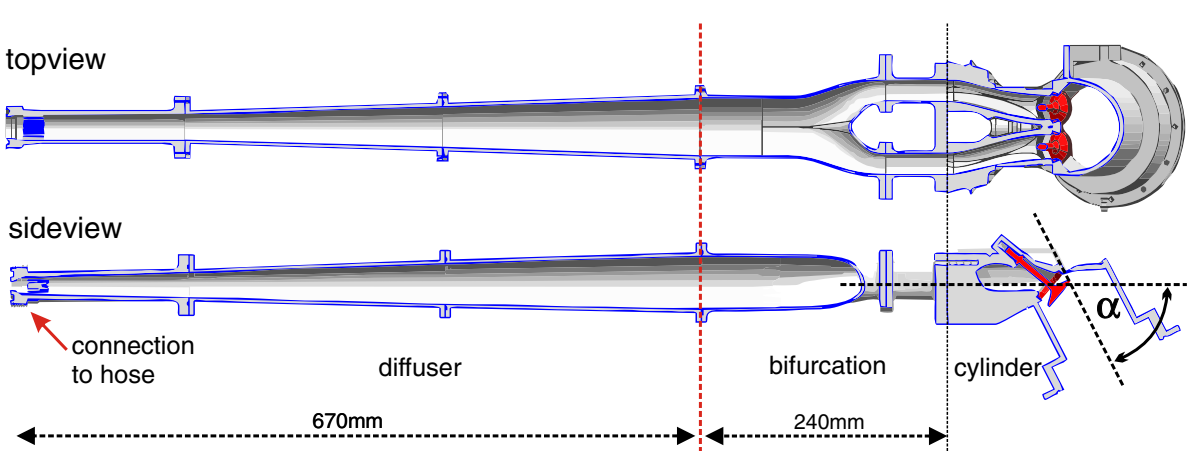




$$
\omega_{\mathrm{L}}(\boldsymbol{r}, t)=\gamma \cdot\left(B_{0}+\boldsymbol{r}(t) \cdot \boldsymbol{G}(t)\right)
$$

Through radio frequency (RF) pulses, the precession axis is tilted, causing the development of transverse magnetization. After the RF-pulse, the transverse magnetization starts to decay and the MR signal can be measured as an echo of the free induction decay in receiver coils. The received signal is a composition of the signals that evolve from every voxel of the entire field-of-view (FOV) and is stored as signal magnitude distribution in raw data space, called $\mathrm{k}$-space. The spatial frequency domain, $\mathrm{k}$-space, is a complex space that besides containing information on the signal magnitude also holds information on the phase angle of all frequency components of the received MR signal.

By a systematic spatial and temporal manipulation of $\omega_{\mathrm{L}}$ within the measurement domain, the MR signal can be spatially encoded. This enables the adjustment of the signal's frequency and phase angle of the spins depending on the position in the FOV. The MR signal transmitted from each position in the FOV can be composed in a way that a Fourier transform can reconstruct the local signal magnitude and phase angle of the signal at every voxel in the FOV.

Bipolar magnetic field gradients can additionally make the phase angle of the MR signal to depend on the local flow velocity. Further information regarding MRI and MRV can be found in Haacke et al. (1999) and Elkins and Alley (2007).

The MRV model was aligned with the patient table of the MR scanner and secured in a fixed position to prevent measurement errors through unintentional movement. Receiver/ Transmitter coils were installed on top of the model and tightened to the patient table of the MR scanner. The MRV model was connected to the hoses and filled with water.

Two different flow rates were chosen for the experiments: 66 and $33 \mathrm{~L} / \mathrm{min}$. The working fluid was heated to $50{ }^{\circ} \mathrm{C}$ to reduce the viscosity and thereby increase the Reynolds number of the flow in the model. The Reynolds numbers inside the straight intake piping were calculated using the bulk flow velocity, the kinematic viscosity of the working fluid, and the diameter of the diffuser at the position just upstream of the bifurcation (diameter $56.3 \mathrm{~mm}$, see red dotted line in Fig. 2). The Reynolds numbers under investigation are $R e=22,500$ and $R e=45,000$.

Each measurement consists of two scans. In the context of this manuscript, an individual scan is the total acquisition time to measure the velocity within all voxels in the volumetric domain. One scan was conducted with fluid flow at the selected flow rate (flow-on scan) and the other scan was conducted without fluid flow (flow-off scan). Both scans are conducted consecutively. The velocity information was encoded in the phase image that was reconstructed by the Fourier transform. Phase angle distortions may result from other influences than from velocity, such as eddy currents and magnetic field inhomogeneity. To remove such effects from the velocity data measured during the flow-on scan, the apparent velocity of the flow-off scan was subtracted from the flow-on scan.

The velocity encoding value (venc), is a parameter that relates the measured phase angle to a velocity. The venc must be chosen such that the highest velocities in the FOV lie below the venc value in order to avoid aliasing effects. By setting the venc value, the magnitude of bipolar magnetic field gradients mentioned above can be chosen. However, the venc should be chosen as low as possible to provide highest signal-to-noise ratio (SNR). Large venc values increase the standard deviation (SD) of the measured velocities as given by:

$$
\begin{aligned}
& \mathrm{SD}\left(v_{i}\right)=\frac{\sqrt{2} \cdot \text { venc }}{\mathrm{SNR}_{\text {mag }} \cdot \pi}, \quad i=x, y, z \\
& \mathrm{SNR}_{\text {mag }}=\frac{\text { mean }(\text { signal })}{2 \cdot \mathrm{SD}(\text { noise })}
\end{aligned}
$$

$\mathrm{SNR}_{\text {mag }}$ is the signal-to-noise ratio of the magnitude image and not of the phase image that carries the velocity information. The noise in the magnitude data is considered to be representative noise of the phase image which can precisely and conveniently be determined for MRV measurements (Haacke et al. 1999). The mean signal value and the value of the standard deviation were determined from representative regions in the 3D datasets (signal magnitude). The venc value was chosen to 1 and $2 \mathrm{~m} / \mathrm{s}$ for $R e=$ 22,500 and $R e=45,000$, respectively, according to the maximum expected flow velocities in the valve gap.

To improve $\mathrm{SNR}_{\mathrm{mag}}$, MR scans were repeated several times (n) with the exact same conditions, which increased $\mathrm{SNR}_{\text {mag }}$ by a factor of $\sqrt{n}$ (Haacke et al. 1999). Therefore, 3 flow-on and flow-off scans for $R e=22,500$ and 4 flowon and flow-off scans for $R e=45,000$ were conducted and averaged. The time for data acquisition was $9 \min 15 \mathrm{~s} /$ scan. The FOV of the measurements was $240 \times 140 \times$ $128 \mathrm{~mm}^{3}$ with a spatial resolution of $1.0 \times 1.0 \times 1.0 \mathrm{~mm}^{3}$. Values for parameters influencing MRV flow determination are provided in Table 2.

The standard deviation of the velocity noise is about $0.02 \mathrm{~m} / \mathrm{s}$ for the individual measurements with $R e=45,000$. In relation to the venc of $2 \mathrm{~m} / \mathrm{s}$, a velocity uncertainty of $1 \%$ is calculated.

\subsection{Coordinate system definition}

Within this work, two coordinate systems are defined: (1) primary $x y z$-coordinate system positioned in the 
Table 2 Parameters and settings of the MRV measurements

\begin{tabular}{ll}
\hline Flow parameters & \\
\hline Fluid & De-ionized water \\
Temperature & $50{ }^{\circ} \mathrm{C}$ \\
Volumetric flow rate & $33 ; 66 \mathrm{~L} / \mathrm{min}$ \\
Reynolds numbers & 22,$500 ; 45,000$ \\
\hline MRV parameters & \\
\hline Field-of-view & $240 \times 140 \times 128 \mathrm{~mm}^{3}$ \\
Spatial resolution & $1.0 \times 1.0 \times 1.0 \mathrm{~mm}^{3}$ \\
Venc & $1 ; 2 \mathrm{~m} / \mathrm{s}$ \\
Time/measurement & $9 \mathrm{~min} 15 \mathrm{~s}$ \\
Number of repetions $(n)$ & $3 ; 4$ \\
Number of vectors & $4.2 \mathrm{e} 6$ \\
\hline
\end{tabular}

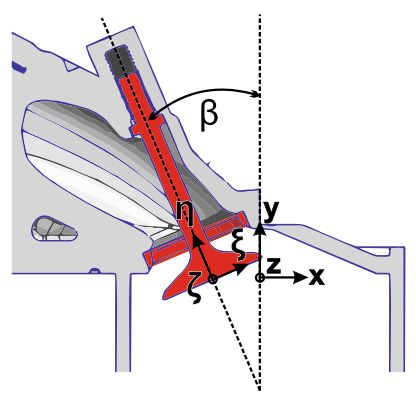

Fig. 3 Definition of the coordinate systems. Cross-sectional view at $z=19 \mathrm{~mm}$ through the symmetry plane of one intake valve

symmetric-axis of the cylinder and (2) $\xi \eta \zeta$-coordinate system positioned in the symmetric axis of one of the intake valves. The origin for the xyz-system lies at the cylinder axis with $y=0 \mathrm{~mm}$ where the cylinder geometry meets the pentroof cylinder head (i.e., firedeck), while the $\xi \eta \zeta$-origin lies at the center-axis of the valve shaft with the $+\eta$ direction along the valve shaft toward the inlet port. Figure 3 shows a detailed cross section of the MRV model in the center plane of one intake valve $(z=19 \mathrm{~mm}$, $\zeta=0 \mathrm{~mm}$ ) to highlight each coordinate system.

\section{Comparability of time-averaged MRV data to ensemble-averaged PIV data}

The focus of this paper is to utilize MRV measurements to investigate the volumetric flow within the inlet system and entering the combustion chamber of a single-cylinder DISI engine. The MRV technique utilized in this work imposes different measurement parameters than those seen in the operating engine; particularly the MRV measurements (1) utilize water as the flow medium, (2) do not include moving boundaries such as the valves or piston, (3) exclude the piston boundary, and (4) consist of a steady flow through the measurement domain. This section addresses these challenges for comparison of MRV and PIV data followed by a validation of the MRV measurements within the central tumble plane of the cylinder chamber (i.e., $z=0 \mathrm{~mm})$.

\subsection{Compressibility effects}

To evaluate the difference of working fluid (i.e., water vs. air), compressibility effects for air were evaluated for the given engine-operating conditions. For such an analysis, the Mach-number $(M a)$ is calculated for the air flow into the engine for PIV measurements. As previously stated, the $\mathrm{CA}$ of interest for this analysis is $270^{\circ} \mathrm{bTDC}$. At $800 \mathrm{RPM}$ and 0.95 bar intake air pressure, the bulk velocity calculated by PIV measurements within the intake piping exhibited a steady-state pipe flow with average air velocity of $10.1 \mathrm{~m} / \mathrm{s}$ from $300^{\circ}$ to $260^{\circ} \mathrm{bTDC}$. This provides an instantaneous air mass flow rate into the engine of $\dot{m}=29.8 \mathrm{~g} / \mathrm{s}$ for $\mathrm{CA}=270^{\circ} \mathrm{bTDC}$. The maximum velocity within the intake system occurs within the valve curtain (Bicen et al. 1985) with the smallest cross-sectional area $\left(9.5 \mathrm{~cm}^{2}\right.$ for the present engine). If the air flow velocity is equally distributed along the entire valve curtain perimeter, the average velocity within the valve gap is estimated to be $13.2 \mathrm{~m} / \mathrm{s}$ and would correspond to $M a=0.038$ $(a=346 \mathrm{~m} / \mathrm{s}$ ). However, within previous studies (El Tahry et al. 1987) and within this work (Sect. 4.2), it is shown that the flow past the valve curtain is not equally distributed. For this work, MRV data reveals that $43.5 \%$ of the air mass flow enters the cylinder over the front side of the valve identified as the overflow (see Fig. 11) covering $25 \%$ of the available cross-sectional area. This would suggest a maximum air flow velocity of $V_{\text {Air,max }}=22.8 \mathrm{~m} / \mathrm{s}$ entering the cylinder and corresponding $M a=0.066$. Thus, the air flow into the engine can be approximated as incompressible (i.e., $\Delta \rho \approx 1.8 \%$ and $M a<0.3$ ), agreeing with that of the water medium in the MRV measurements.

\subsection{Piston boundary and movement}

As previously mentioned, the piston is removed within the MRV model and the flow exits through the bottom of the cylinder chamber. Within the optical engine, the annular inlet flow enters the cylinder chamber and this flow is redirected by the cylinder wall and piston surface, creating a large-scale tumble motion as shown in Fig. 4 and described in detail in Baum et al. (2014). The PIV data shown in Fig. 4 is the ensemble average flow field based from 2,700 cycles at $270^{\circ} \mathrm{bTDC}$. This large-scale tumbling 


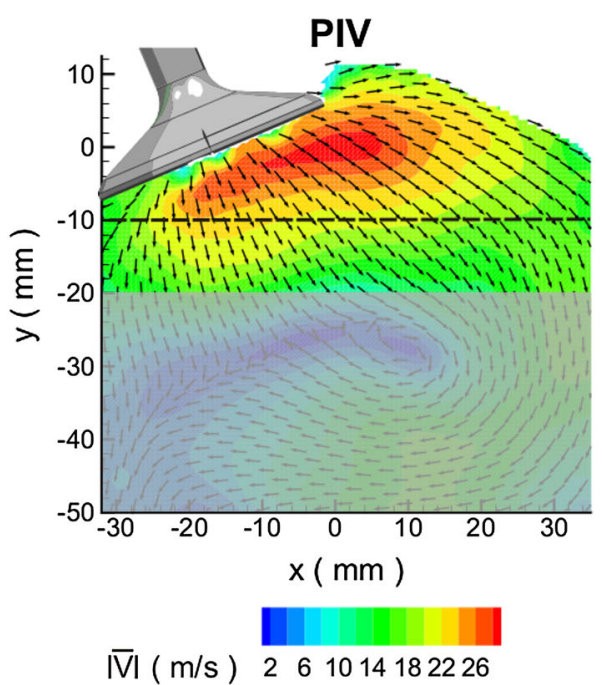

Fig. 4 2D contour plot in the symmetry plane of the model. PIV and MRV at $270^{\circ}$ bTDC. Dashed lines at $y=-10 \mathrm{~mm}$ reveal the lines for which velocity profiles were extracted in Fig. 5. Flow velocities are not considered for comparison within the shaded region where the MRV flow deviates from the PIV flow due to the absence of the piston

motion within the center of the cylinder chamber does not exist within the MRV measurement volume (see Fig. 4) due to the absence of the piston boundary and its movement. Therefore, the MRV data should only be evaluated within the measurement volume where the flow is not influenced by the piston. As shown in Fig. 4, the flow pattern within the MRV measurements begins to significantly deviate from the PIV measurements below $y=-20 \mathrm{~mm}$. Therefore, within this manuscript, the flow measurements obtained from MRV will only be evaluated above $y=-20 \mathrm{~mm}$.

\subsection{Valve movement}

For the current measurements, the MRV model has a fixed valve lift of $9.21 \mathrm{~mm}$ corresponding to the valve position at $270^{\circ} \mathrm{bTDC}$. This valve position is near its maximum lift of $9.5 \mathrm{~mm}$, which occurs at $250^{\circ} \mathrm{bTDC}$ within the optical engine. As stated within previous studies (Fukutani and Watanabe 1982; Bicen et al. 1985; El Tahry et al. 1987), the influence of valve motion is primarily regarded to provide variations in the valve gap spacing and not, as a first-order effect, cause transients of the velocity profiles at the exit of the valve curtain. Furthermore, at $270^{\circ} \mathrm{bTDC}$, the valve translational velocity is $0.01 \mathrm{~m} / \mathrm{s}$, which is significantly lower than the estimated air velocity exiting the valve gap. Thus, it is expected that valve movement at $270^{\circ} \mathrm{bTDC}$ will have a minimal influence on the resulting inlet flow field and can therefore be neglected.

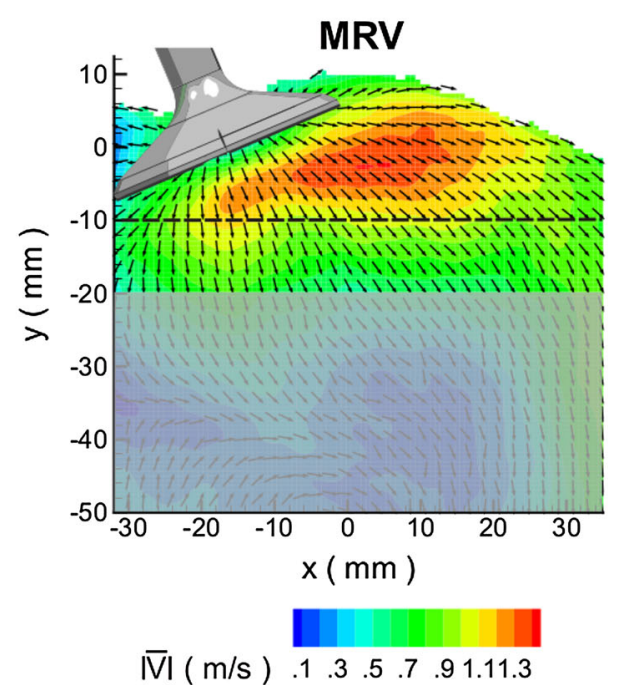

surface. Velocity vectors (every 3rd vector shown) are displayed with a fixed vector length for a better visualization of the flow topology. Intake valves are not present in the symmetry plane. They are visualized to give the reader an idea of its positions relative to the vector field

\subsection{Steady flow}

The fluid flow within the MRV measurements system represents a steady-state flow, while the flow within the engine inlet can be unsteady throughout induction. However, Bicen et al. (1985) and El Tahry et al. (1987) established that a quasi-steady flow assumption is valid for many parts of the intake stroke, particularly when the piston acceleration is near zero (i.e., near $270^{\circ} \mathrm{bTDC}$ ). Flow measurements from El Tahry et al. (1987) within a motored engine further argued that the quasi-steady flow phase near maximum valve lift is the induction phase where most of the cylinder charge is inducted into the engine. Thus, the steady flow assumption has been one of the key assumptions enabling previous flow studies within engine inlet systems (Bicen et al. 1985; Khalighi et al. 1986; El Tahry et al. 1987; Tindal et al. 1988; Cheung et al. 1990; Chen et al. 1995; Nadarajah et al. 1998; Pajković and Petrović 2008) and is argued as a valid assumption for the MRV measurements presented in this work.

\subsection{Validation of MRV data}

The representative ensemble mean flow fields at $270^{\circ}$ bTDC for MRV and PIV measurements are shown in Fig. 4. The PIV phase-averaged measurements are based on 2,700 engine cycles, while MRV data provides ensemble mean velocity information. Since the fluids of both experiments (MRV and PIV) strongly differ in density and viscosity, a direct comparison of the measured velocities is 


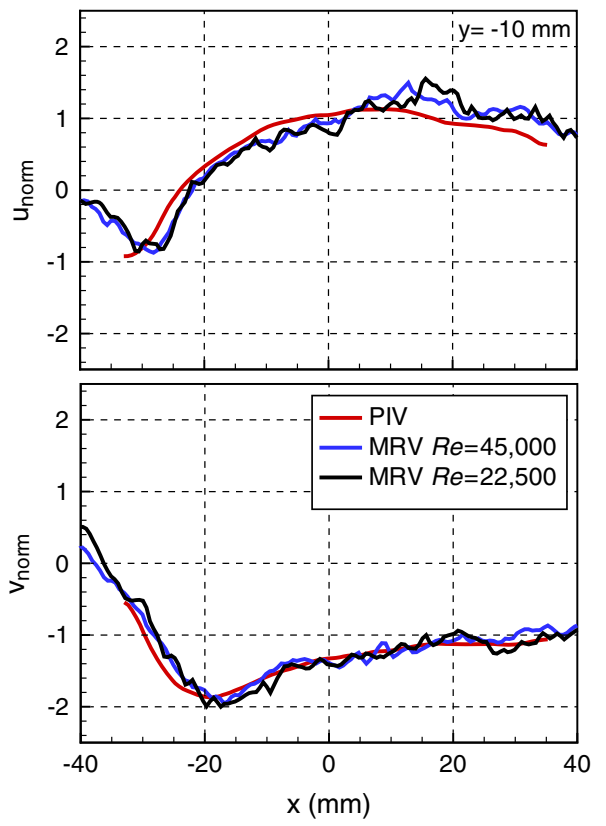

Fig. 5 Normalized $u$ - and $v$-velocity profiles extracted along the horizontal line $y=-10 \mathrm{~mm}$ for the PIV and MRV datasets. The factors used for velocity normalization $(N F)$ can be found in Table 3

not possible. Usually the comparison of incompressible flows of different fluids is conducted on the basis of the Reynolds number of each dataset. The Reynolds number of the in-cylinder flow is often not well defined due to geometric complexities, moving boundaries, and unsteady flows within the engine. Alternatively, it is possible to match Reynolds numbers within the straight piping of the intake system, but could also be argued that this position is too far upstream from the in-cylinder flow. Therefore, comparison of the MRV and PIV measurements is conducted by analyzing normalized in-cylinder velocity profiles within the measurement volume.

The comparison of normalized in-cylinder velocity profiles is performed for two different flow rates of water into the MRV measurement volume. This is performed to establish flow rate, or Reynolds number, independence on the resulting in-cylinder velocity profiles. The Reynolds number of the inlet flow is calculated using the bulk velocity (2D: PIV, 3D: MRV) measured within the straight pipe of the intake system $390 \mathrm{~mm}$ upstream of the engine (red dotted line in Fig. 2). This is the location at the end of the diffusor in the MRV model and is also the location where PIV measurements are performed in the intake system. The flow rate was adjusted to provide $R e=22,500$ and 45,000 for the MRV measurements, while for PIV measurements $R e \approx 37,200$. The Reynolds number calculated from PIV measurements are regarded as an estimate, since only the $2 \mathrm{D}$ velocity is measured. For a more accurate calculation, $3 \mathrm{C}$ velocities are necessary over the entire
Table 3 Spatial-averaged $u$ - and $v$-velocity components, averaged along a horizontal line at $y=-10 \mathrm{~mm}(x=-33 \mathrm{~mm}$ to $35 \mathrm{~mm}, z=0 \mathrm{~mm})$. The normalization factors $(N F)$ are calculated from the spatial-averaged $u$ - and $v$-velocity components and used to normalize the velocity components

\begin{tabular}{llcc}
\hline Dataset & spat.-avg. $u(\mathrm{~m} / \mathrm{s})$ & spat.-avg. $v(\mathrm{~m} / \mathrm{s})$ & $N F(\mathrm{~m} / \mathrm{s})$ \\
\hline PIV $_{R e \approx 37,200}$ & 8.29 & 16.56 & 12.43 \\
MRV $_{R e=22,500}$ & 0.20 & 0.39 & 0.30 \\
MRV $_{R e=45,000}$ & 0.42 & 0.78 & 0.60 \\
Scaling Factor (SF) PIV/MRV $_{R e=22,500}$ & 41.70 \\
Scaling Factor (SF) PIV/MRV & & 20.64 \\
\hline
\end{tabular}

3D domain. Therefore, it was desired that the two Reynolds numbers for the MRV measurements were above and below the Reynolds number value estimated in the PIV measurements.

The velocity normalization was conducted by referencing the velocity field to a representative in-cylinder velocity value for each dataset, namely the normalization factor $(N F)$. The $N F$ is defined as the arithmetic mean value of the spatial-averaged $u$ - and $v$-velocity components along a horizontal line $(x=-33 \mathrm{~mm}$ to $35 \mathrm{~mm}, y=$ $-10 \mathrm{~mm}, z=0 \mathrm{~mm}$ ) shown in Fig. 4. The velocities along the selected line are representative for in-cylinder velocities produced by the annular flow past the intake valves and is a region least influenced by the absence of the piston boundary in the MRV measurements. The spatial-averaged $u$ - and $v$-velocity components and the NF for the PIV and both MRV datasets are listed in Table 3.

The ratio between the $u$-, $v$-, and $N F$-velocity components of the PIV and MRV datasets, denoted as scaling factor $(S F)$, is also listed in Table 3. A $S F$ of 41.70 and 20.64 can be assumed for the MRV datasets of $R e=$ 22,500 and $R e=45,000$, respectively. Referring to Fig. 4, the calculated $S F$ can be used to scale the velocity magnitudes of the $\mathrm{MRV}_{R e=45,000}$ dataset to the corresponding velocity values of the PIV dataset. To evaluate the accuracy of this rescaling procedure, the ratio of bulk air to water velocity measured within the intake piping (i.e., red line Fig. 2) is calculated and compared to SF values. With the bulk air velocity $(10.1 \mathrm{~m} / \mathrm{s})$ and bulk water velocities $\left(\mathrm{MRV}_{R e=22,500}=0.23 \mathrm{~m} / \mathrm{s}\right.$ and $\left.\mathrm{MRV}_{R e=45,000}=0.45 \mathrm{~m} / \mathrm{s}\right)$, the velocity ratios (43.9 for $\mathrm{MRV}_{R e=22,500}$ and 22.4 for $\left.\mathrm{MRV}_{R e=45,000}\right)$ are in great agreement with the scaling factors reported in Table 3. Therefore, the recommended scaling procedure is regarded as acceptable.

Figure 5 shows the normalized $u$ - and $v$-velocity component profiles along the $y=-10 \mathrm{~mm}$ horizontal line. The normalized velocity profiles are shown to collapse to one representative curve, revealing a parallel, almost congruent progression especially for the $v$-velocity. These results also 

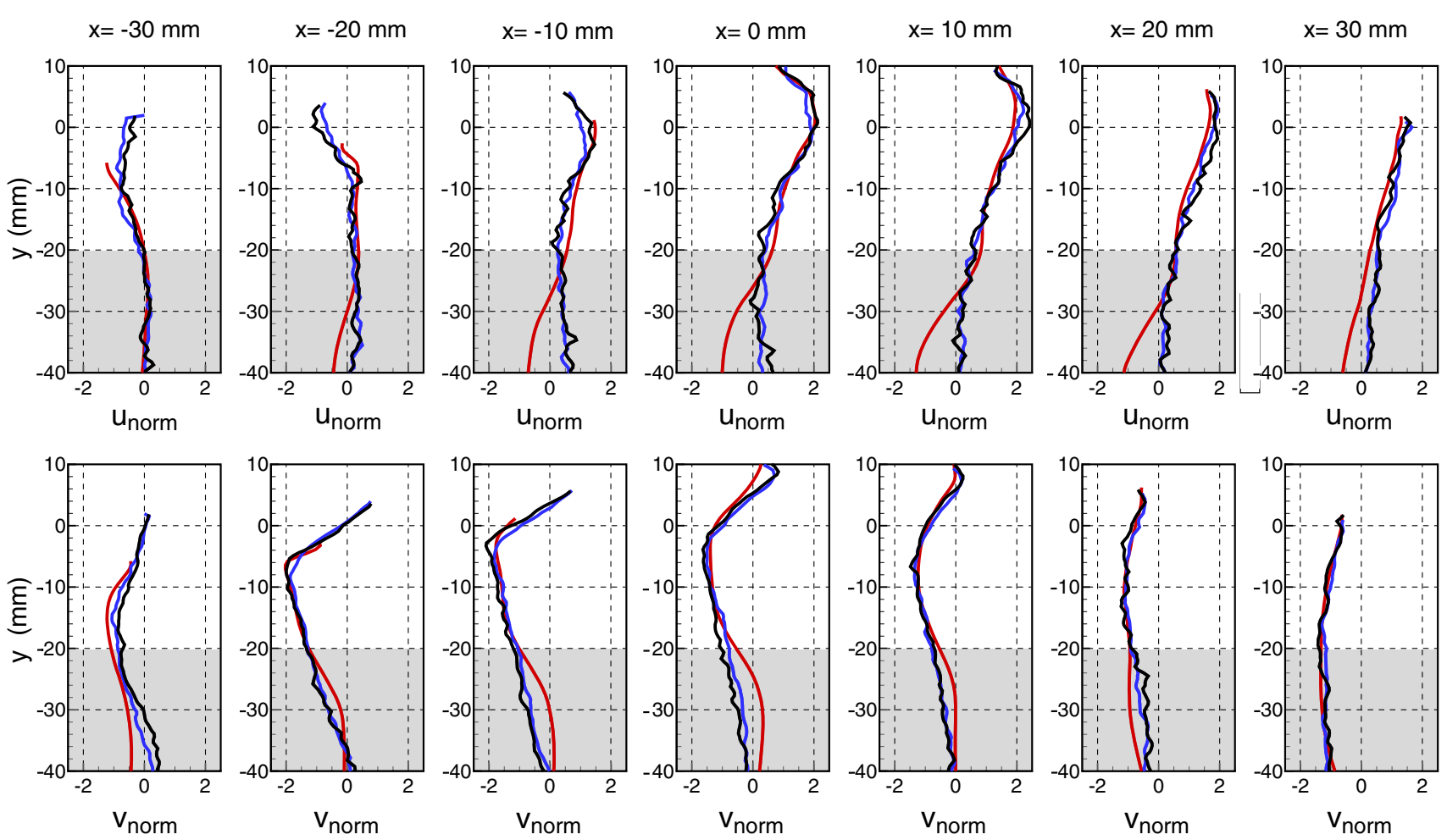

Fig. 6 Normalized $u$ - and $v$-velocity component profiles along vertical lines for different $x$-positions within the $z=0 \mathrm{~mm}$ plane. Normalized profiles for all measurement sets collapse to one curve confirming the excellent agreement in Fig. 5. Reynolds number independence can be assumed due to the almost congruent

show that Reynolds number independence can be assumed for the aforementioned flows.

Comparison of normalized velocity component profiles is further performed in the $y$-direction for different $x$ positions (every $10 \mathrm{~mm}$ ) and is shown in Fig. 6. Velocities are normalized by the same velocity component values reported in Table 3 . The top row shows $u$-velocity profiles, while the bottom row shows $v$-velocity profiles. As mentioned in Sect. 3.2, MRV measurements are disregarded below $y=-20 \mathrm{~mm}$ due to the absence of the piston. The velocity profiles above $y=-20 \mathrm{~mm}$ show excellent accordance of all three datasets and further demonstrate the validity of the MRV measurements. These results also demonstrate that the named assumptions between MRV and PIV measurements are credible. Thus, it is concluded that the MRV flow measurements conducted with water produce reliable flow results and are deemed suitable to investigate the $3 \mathrm{D}$ inlet flow within the intake system at the CA under investigation. The analysis within the remainder of this manuscript is based on the assumption that agreement of the in-cylinder flows also implies similar velocity distributions within the cylinder chamber and inlet system in $3 \mathrm{D}$ space. progression of the normalized velocities of all three datasets. Velocities within the shaded region are not considered due to the absence of the piston boundary in the MRV model. The factors used for velocity normalization $(N F)$ can be found in Table 3

\section{Results}

The MRV data is further analyzed to investigate the 3D fluid motion within the intake system and entering the cylinder chamber. Within the remainder of the manuscript, the MRV measurements are reported for $R e=45,000$. As previously mentioned, MRV data are not analyzed below $y=-20 \mathrm{~mm}$ within the cylinder chamber because the flow below this region diverts from the flow velocities in the engine due to the absence of the piston boundary within the MRV model. The velocity magnitudes of the MRV measurements can be calculated back to the real-engine flow velocity using the scaling factor (SF).

\subsection{Tumble, cross-tumble and swirl plane flow distributions}

Flow field images are first analyzed within selected tumble, cross-tumble, and swirl planes to describe the 3D nature of the inlet flow entering the cylinder chamber. The flow within the mid-valve tumble plane at $z=19 \mathrm{~mm}$ is shown in Fig. 7. The flow field for the adjacent intake valve is not shown for economy of presentation, but exhibits identical 


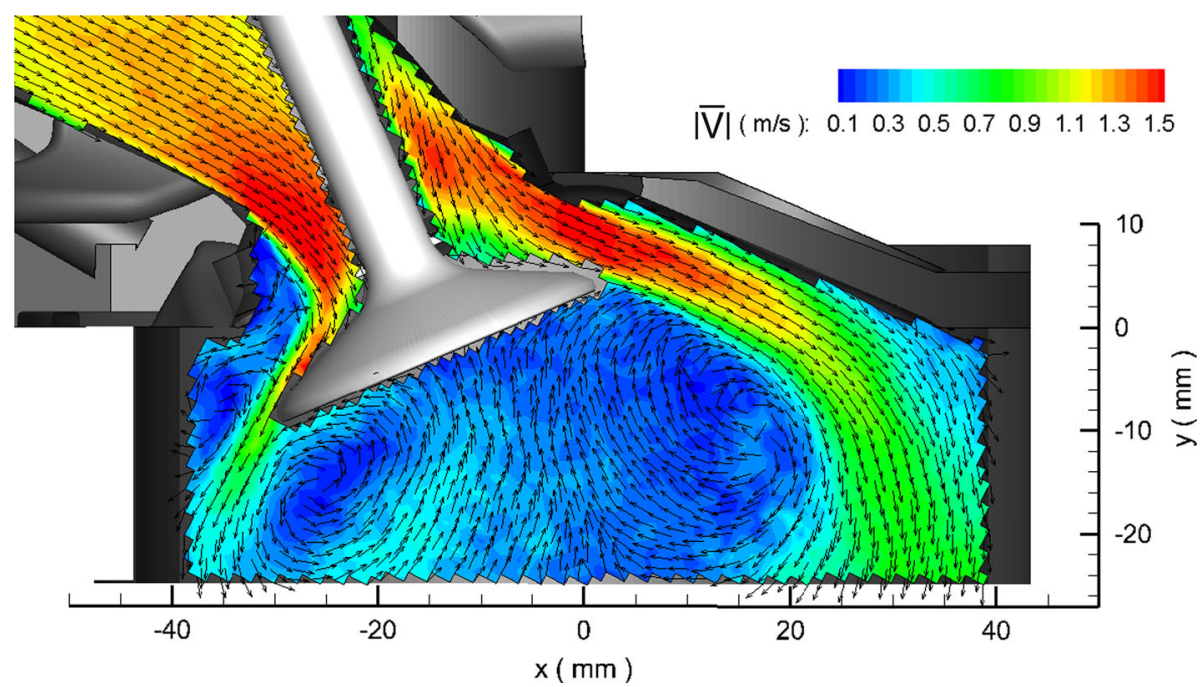

Fig. 7 Tumble flow plane at mid-valve position $(z=19 \mathrm{~mm})$ showing the intake flow in the vicinity of the intake valve. Highest flow velocities appear in the valve curtain of the overflow region $(x=0 \mathrm{~mm}, y \approx 10 \mathrm{~mm})$. A recirculation zone exists in the underflow region $(x \leq-25 \mathrm{~mm}, y \approx 0 \mathrm{~mm})$ where mass flow is re-entering the inlet-channel up to the valve seat. Velocity vectors (every 3rd vector shown) are displayed with a fixed vector length for better visualizing of the flow topology. The velocity magnitude can be scaled to realengine velocity using the $S F$
Fig. 8 Contour plot of the cross-tumble plane at $x=$ $-10 \mathrm{~mm}$ showing the inlet flow entering the cylinder chamber over both intake valves.

Velocity vectors (every 3rd vector shown) are displayed with a fixed vector length to better visualize the flow topology. The velocity magnitude can be scaled to realengine velocity using the $S F$. Two counter rotating vortices are produced on each side of the intake jet, the vortex centers are marked by $x$

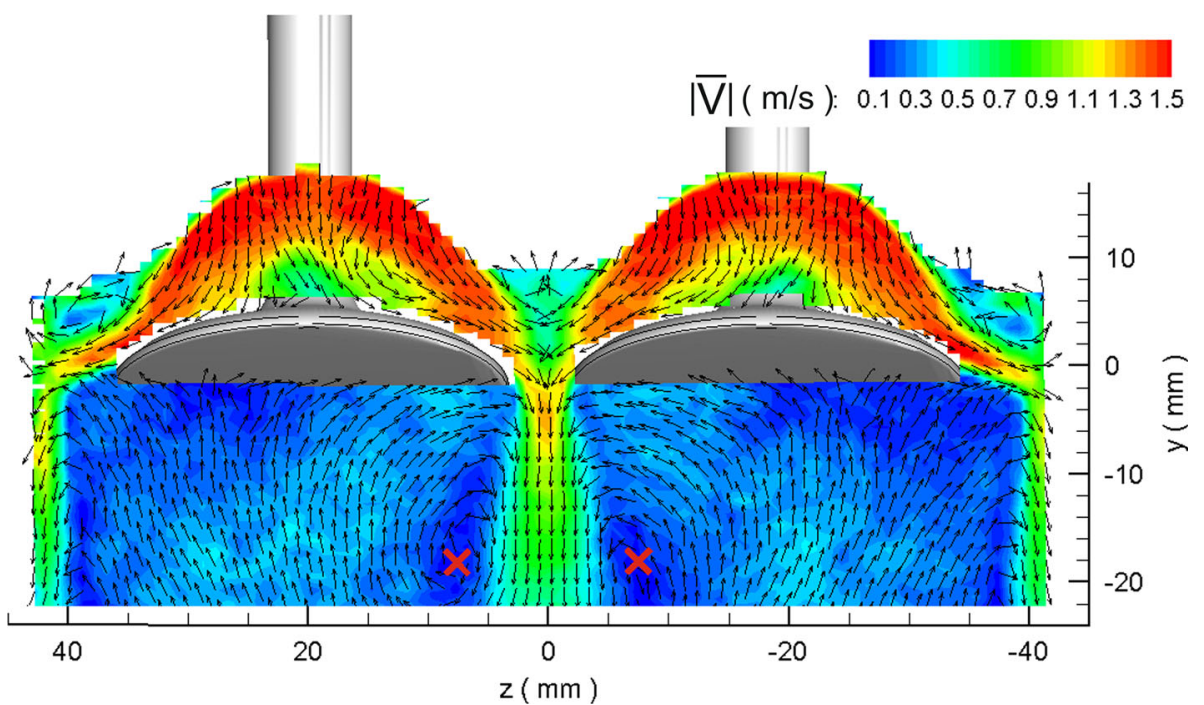

flow patterns as those shown in Fig. 7. The velocity vectors (every 3rd vector shown) in Fig. 7 have a fixed vector length to better visualize the flow pattern, while the $3 \mathrm{C}$ velocity magnitude is shown by the color scale.

A quasi-steady, uniform annular flow exists within the intake manifold (top-left in Fig. 7) and is aligned parallel with the manifold $\left(27^{\circ}\right.$ to the $x$-axis). The uniform flow field is disrupted by the valve stem and the valve head surface. The flow velocity increases in the periphery of the valve stem as the flow approaches the smaller cross-sectional areas of the valve gap. The angle of the manifold guides the majority of the flow through the valve gap over the front side of the valve $(\xi>0 \mathrm{~mm})$ and the flow enters the cylinder chamber near the central cylinder axis $(x=0 \mathrm{~mm})$. This flow is termed overflow. The velocity magnitude is largest within the valve gap of the overflow region and the flow entering the cylinder extends to the opposite side of the cylinder wall. The flow creates a clockwise vortical motion with the vortex center located slightly off cylinder axis and beneath the intake valve. Without complementary measurements within the middle valve plane in the operating engine, it cannot be quantified that this vortical motion is a part of the large-scale clockwise tumble motion or a separate vortical flow structure resulting from flow separation from the valve surface. On the left side of the image, the flow approaching the valve is 
redirected at the valve surface, and a small portion of the flow enters the cylinder chamber from the back side of the valve (i.e., $\xi<0 \mathrm{~mm}$ ). This flow is termed underflow. The overflow and underflow regions are further discussed in Sect. 4.2. Within this viewing plane, the underflow consists of a narrow flow channel of high velocities entering the cylinder and producing a counter-clockwise vortical motion directly beneath the valve as the flow discharges near the valve surface.

Before the underflow is redirected by the valve surface, the flow separates from the intake port geometry and a large recirculation zone is present between the valve seat and valve head. A portion of the underflow that enters the cylinder is redirected by the cylinder wall and is guided into the recirculation zone. The recirculation zone extends from the cylinder chamber into the intake port, covering a large area within the valve gap. Recirculation zones within the entire annular area between the valve seat and valve surface (i.e., valve curtain) are analyzed in Sect. 4.2.

The inlet flow entering the cylinder chamber over both intake valves is visualized within the cross-tumble plane $(x=-10 \mathrm{~mm})$ shown in Fig. 8. Velocity vectors (every 3rd vector shown) have a fixed length and the $3 \mathrm{C}$ velocity magnitude is shown by the color scale. Velocity magnitude is largest within the intake port just above the valve surface where the cross-sectional area decreases $(y \approx 10 \mathrm{~mm}$, see also Fig. 7). The fluid motion within the intake port is redirected along the valve surface and the fluid discharges into the cylinder chamber along the valve periphery. Along the central cylinder axis $(z=0 \mathrm{~mm})$, the annular flow extending from both intake channels impinge on one another creating a recirculating flow above the impinging flows and a strong downward channel-like flow between the two intake valves. This strong downward channel flow is often referred to as intake jet within the central tumble plane (Baum et al. 2013, 2014; Voisine et al. 2011). The largest velocities within the intake jet occur where the annular flows from each valve merge into one congruent flow-like structure directly in between the intake valves along the central cylinder axis. The thickness of the intake jet (i.e., z-direction) broadens with vertical distance within the FOV. Two counter rotating vortices are produced on each side of the intake jet and the vortex centers are clearly marked by $\times$ in Fig. 8 . These vortices lie within the large recirculating flow regions with low velocity magnitude located underneath each intake valve.

On the opposite side of each intake valve $(z= \pm 35 \mathrm{~mm})$, the annular flow over the valve discharges with higher velocity magnitudes than shown within the intake jet. The annular flows at these locations are quickly redirected by the cylinder wall located at $z= \pm 43 \mathrm{~mm}$. A portion of the flow is redirected toward the cylinder head forming a recirculation zone, while the rest of the flow is

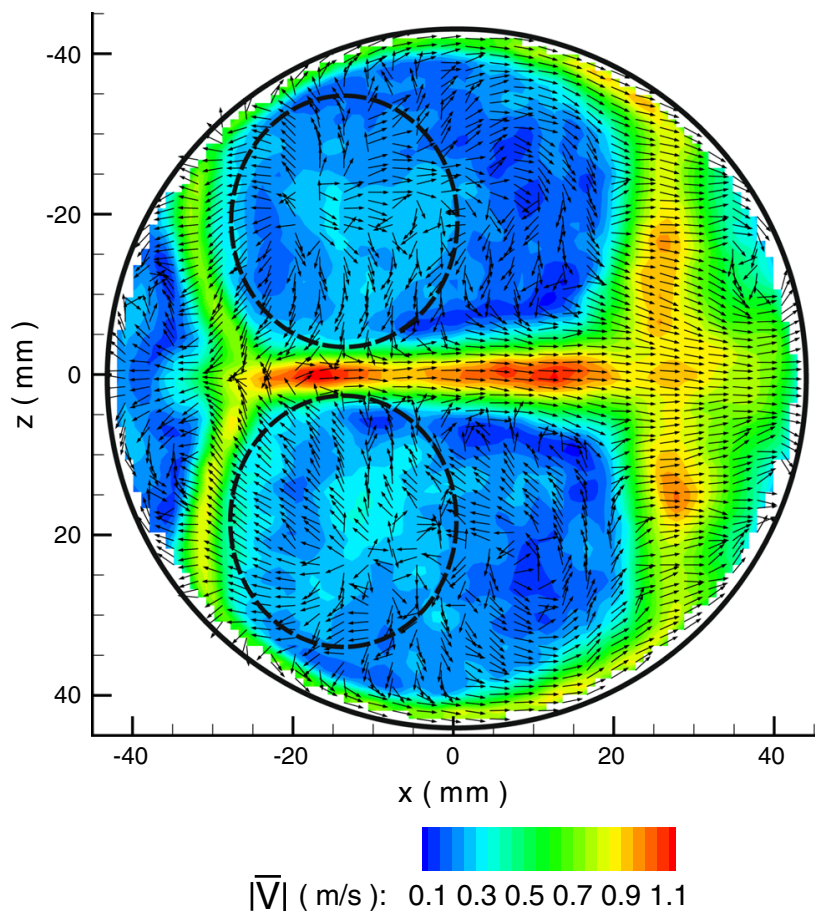

Fig. 9 Contour plot of the swirl plane flow at $y=-10 \mathrm{~mm}$. The positions of the intake valves is marked with dotted lines. The intake jet becomes visible in the central position of the cylinder $(x=-20 \mathrm{~mm}$ to $x=20 \mathrm{~mm}, z=0 \mathrm{~mm}$ ). Velocity vectors (every 3rd vector shown) are displayed with a fixed vector length for better visualizing of the flow topology. The velocity magnitude can be scaled to real-engine velocity using the $S F$

directed downward into the cylinder chamber near the cylinder walls. The recirculation zones on each side of the chamber and the flows directed along the cylinder walls appear symmetric with the cylinder axis.

Figure 9 shows the flow distribution within the swirl plane just below the intake valves at $y=-10 \mathrm{~mm}$. An outline of the intake valves are shown to provide an understanding of the flow distribution relative to the valve locations. Velocity vectors (every 3rd vector shown) have a fixed length, and velocity magnitude is shown by the color scale. The in-cylinder flow is symmetric around the $z=$ $0 \mathrm{~mm}$ centerline. The high velocities associated with the intake jet are shown along the $z$-axis and resemble a jet-like flow traveling across the cylinder away from the intake valves. The overflow produced over the intake valves is evident by the high velocity region shown on the opposite side of the cylinder axis (i.e., $x>20 \mathrm{~mm}$ ). From Figs. 4 and 7 , it is understood that the velocities within intake jet and overflow contain a large vertical velocity component. Low velocity regions exist beneath each valve and are considered to be in the wake region behind the intake valve surface. The annular flow extends into the underflow region and is shown around the periphery of the valve outline near $x=-30 \mathrm{~mm}$. This is the narrow annular flow channel 

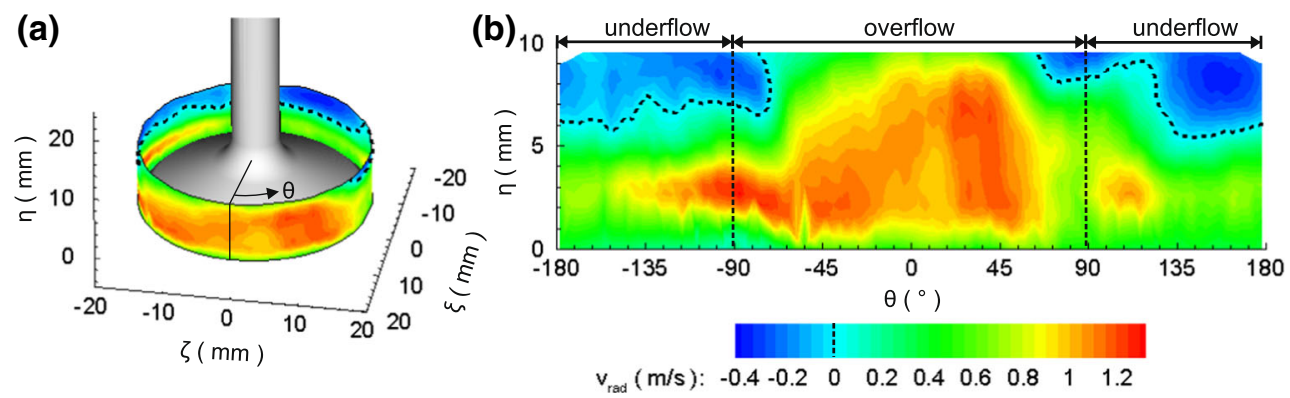

Fig. 10 a Annular iso-countor (17.5 $\mathrm{mm}$ radius) around the valve curtain of one intake valve (at $z=19 \mathrm{~mm}$ ). b Annular contour plot projected on a $2 \mathrm{D}$ plane. The contour shows radial velocity plotted over the valve lift $\eta$ and the azimuth $\Theta$. A boundary (dotted line) is superimposed onto the iso-contour to identify regions of negative radial velocity. Distinctive areas of negative radial velocity in the underflow region consist of flow re-entering the valve curtain region. The radial velocity can be scaled to real-engine velocity using the $S F$ entering the cylinder chamber from the underflow and also contains a large vertical velocity component (see Fig. 7). A region of lower velocities exists near the cylinder wall just beyond the annular channel of the underflow. This is regarded as the flow that is promptly entrained into a recirculation region near the cylinder wall, which is shown in Fig. 7 and further discussed in Sect. 4.3.

\subsection{Flow distribution through valve curtain}

For engine inlet flows, it is important to quantify the flow discharging past the valve and into the cylinder chamber. The flow through the valve curtain is analyzed to quantify velocities and mass flow rates entering the cylinder chamber around the entire valve curtain perimeter. The valve curtain is defined as the annular area between the valve head and valve seat (Heywood 1988). For this analysis, the $\xi \eta \zeta$-coordinate system is used, which is positioned in the symmetric axis of one intake valve. The inlet flow past the valve curtain for each intake valve is symmetrically similar; thus, for brevity, the flow past the valve curtain is only analyzed for the intake valve symmetric around $z=19 \mathrm{~mm}$ (i.e., $\zeta=0 \mathrm{~mm}$ ).

Figure 10a shows the radial velocity along a fixed isocontour placed around the perimeter of the valve curtain. The iso-contour represents the exit of the valve curtain area and consists of a cylinder perimeter with $17.5 \mathrm{~mm}$ radius (compared to the $16.5 \mathrm{~mm}$ valve radius) and height of the valve lift (i.e., $9.21 \mathrm{~mm}$ ). Due to limited spatial resolution, it was not possible to consistently resolve the velocities near solid boundaries. Therefore, with a larger iso-contour radius, the radial velocities were well-resolved along the entire valve lift. Figure $10 \mathrm{~b}$ shows the iso-contour as a $2 \mathrm{D}$ surface along the azimuth $(\Theta)$. This polar coordinate system is concentric about the valve axis and the polar axis is aligned with the $\zeta=0 \mathrm{~mm}$ plane; $\Theta$ increases counterclockwise around the valve and ranges from $-180^{\circ} \leq \Theta \leq 180^{\circ}$. The overflow region $\left(-90^{\circ} \leq \Theta \leq 90^{\circ}\right)$ and underflow region $\left(|\Theta| \geq 90^{\circ}-180^{\circ}\right)$ are clearly identified in Fig. 10b. For a clear perspective, the points on the iso-contour from the mid-valve plane shown in Fig. 7 are located at $\Theta=0^{\circ}$ and $180^{\circ}$, while the points on the isocontour from the cross-tumble plane shown in Fig. 8 are located at $\Theta= \pm 60^{\circ}$. A positive radial velocity represents a flow entering the cylinder chamber, while a negative radial velocity represents a flow re-entering the valve curtain region from the cylinder chamber (i.e., recirculation zone). A boundary (dotted line) is superimposed onto the iso-contour to identify regions of negative radial velocities.

At the exit of the valve curtain, the overflow region exhibits large positive radial velocities. Over the entire height of the valve gap, large radial velocities are shown from $-45^{\circ} \leq \Theta \leq 45^{\circ}$. Velocity magnitude starts to decrease beyond $\Theta= \pm 45^{\circ}$, but large radial velocities are still seen closer to the valve head $(<5 \mathrm{~mm})$ until $\Theta= \pm 130^{\circ}$. The distribution of large velocities along the iso-contour is not uniformly symmetric about the polar axis. A region of larger radial velocities extends further toward negative $\Theta$ values. Thus larger flow velocities are shown to exit toward the direction of the nearby cylinder wall (i.e., $\Theta=-90^{\circ}$ ), than toward the direction of the adjacent intake valve. As seen in Fig. 8, annular flows from each intake valve impinge on one another within the region between the two intake valves. This impinging flow reduces the radial velocity magnitude exiting the valve curtain region from $\Theta=60^{\circ}$ to $100^{\circ}$. Regions of negative radial velocity are primarily seen closer to the cylinder head within the underflow region (i.e., $\eta>6 \mathrm{~mm},|\Theta|>90^{\circ}$ ). These negative velocities identify the recirculation zones existing along the perimeter of the valve curtain and reveal that in-cylinder flow velocities re-enter the inlet region over $180^{\circ}$ around the valve perimeter.

The mass flow rate around the perimeter of the valve curtain is calculated to further quantify the flow 


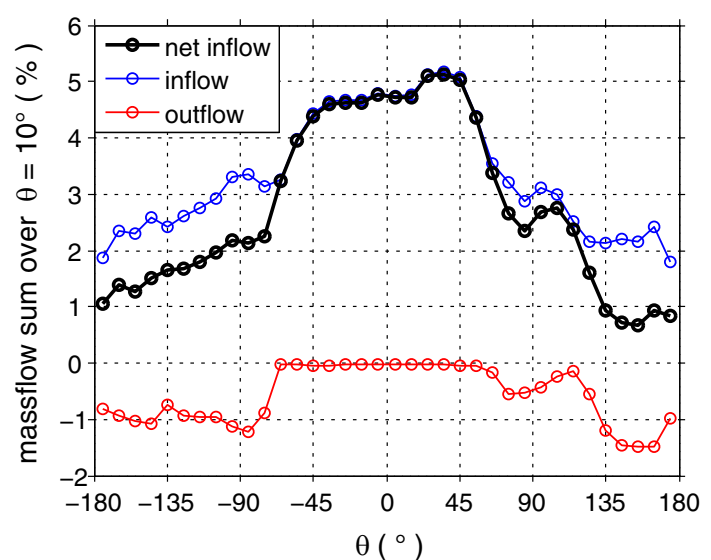

Fig. 11 Total mass flow entering the cylinder chamber (blue), total mass flow exiting the cylinder via flow recirculation back into the intake system (red), and net flow rate discharging into the cylinder (black) with respect to the azimuth along the iso-contour. Values are calculated for $\Theta=10^{\circ}$ intervals

discharging into the cylinder chamber. The mass flow is calculated from the water density $\left(\rho=0.988 \mathrm{~kg} / \mathrm{dm}^{3}\right)$, local radial velocity, and the local cross-sectional area. Figure 11 shows the total mass flow entering the cylinder chamber (blue), the total mass flow exiting the cylinder via flow recirculation back into the intake system (red), and the net flow rate discharging into the cylinder (black) with respect to the azimuth along the iso-contour. Values shown are the percentage mass flow of the net cylinder inflow and values are calculated for $\Theta=10^{\circ}$ intervals. Mass flow rate into the cylinder chamber is greatest within the overflow region, especially between $-60^{\circ} \leq \Theta \leq 60^{\circ}$, where only positive radial velocity exist. The mass discharged into the cylinder significantly decreases by $40 \%$ as $\Theta$ approaches the underflow region. This is due to lower velocity magnitudes as well as the presence of recirculation regions (negative radial velocities) as $\Theta$ approaches $\pm 90^{\circ}$ (Fig. 10). The mass recirculating back into the inlet (red line) is first present near the ends of the overflow region and extends through the entire length of the underflow region. The recirculating flow significantly reduces the net cylinder inflow by nearly $50 \%$ in the underflow region.

The mass flow exiting the cylinder via recirculation has large implications on the cylinder charge filling and possible contributions to cyclic variations of the in-cylinder flow development (El Tahry et al. 1987; Heywood 1988). Although the MRV data presented here only provides ensemble average flow measurements at a phase-locked $\mathrm{CA}$, quantification of the flow discharging from the intake curtain is vital for optimizing the design of engine intake geometries. The focus of future investigations employing MRV measurements within the engine model will investigate inflow phenomena for various valve lifts, moving valves, and resolving flow fluctuation information within the near valve regions.

\subsection{Recirculation zones in-cylinder chamber and valve curtain}

As already shown, the recirculation zones within the valve curtain reduce charge flow rates into the cylinder chamber. The existence of these recirculation zones near the cylinder head have been revealed with previous methods employing LDA measurements (Bicen et al. 1985; Dittmeyer and Tropea 1990; Chen et al. 1995; Mahmood et al. 1996) but were not analyzed in 3D space. Thus, it is crucial to identify regions of recirculated flow and understand their influence on volumetric efficiency as well as the developing in-cylinder flow pattern. Within this section, recirculation zones are identified in 3D space inside the entire cylinder chamber. The recirculation zones presented are defined as any location with positive $\eta$-velocities, indicating velocities directed toward the intake manifold. Although this criteria to identify recirculation zones is different than presented in Sect. 4.2 (negative radial velocities to valve curtain), the velocity direction is similar as the recirculated flow is directed inward and upward within the intake manifold.

A large recirculation zone is present in the underflow region near the pentroof and cylinder wall, as mentioned in Sect. 4.1. To obtain a better understanding of the entire 3D recirculating mass flow in the vicinity of the intake valves, iso-surfaces with fixed velocity values are visualized from two different perspectives in Fig. 12a. The iso-surfaces of $\eta$-velocity magnitudes $(0.02,0.15,0.25$ and $0.35 \mathrm{~m} / \mathrm{s})$ represent positive $\eta$-velocities along the valve shaft toward the inlet port. Both intake valves and one valve seat are displayed. Note that, for a clearer illustration, the recirculating mass flows occurring below the bottom of the valve surface are blanked in the figure.

Figure $12 \mathrm{~b}$ shows the recirculation zones as a number of layers parallel to the bottom of the valve surface in $\eta=2 \mathrm{~mm}$-steps starting from $\eta=-2 \mathrm{~mm}$. Only the zones of positive $\eta$-velocities are shown, others are shaded white for a clearer illustration. The value $\eta=0 \mathrm{~mm}$ corresponds to the bottom valve surface. Gray areas indicate the presence of the valve.

Two circular-shaped recirculation zones are shown in the $\eta=-2 \mathrm{~mm}$ layer. These recirculation zones, caused by the vortical flow motion inside the cylinder, are also shown in Figs. 7 and 8. The dominant recirculation zone appears on the backside of the valves in the underflow region close to the cylinder wall. This recirculation zone is visualized in the bottom-center of the $\eta$-slices in Fig. 12b (slices $-2 \mathrm{~mm} \leq \eta \leq 8 \mathrm{~mm}$ ) and in the bottom right corner of Fig. 12a. It retains its size and position over almost six step- 
Fig. 12 a $\eta$-velocity isosurfaces representing recirculating mass flow $(\eta$ velocity $>0 \mathrm{~m} / \mathrm{s}$ ) during intake stroke inside the cylinder chamber and valve gap. Note that recirculating mass flow occurring underneath the valves $(\eta<0 \mathrm{~mm})$ is not shown for a clearer illustration. $\mathbf{b} \eta$-layers of the recirculation zones in $2-\mathrm{mm}$ steps starting from $\eta=-2 \mathrm{~mm}$. Gray areas indicate the presence of the valve. The $\eta$ velocity can be scaled to realengine velocity using the $S F$
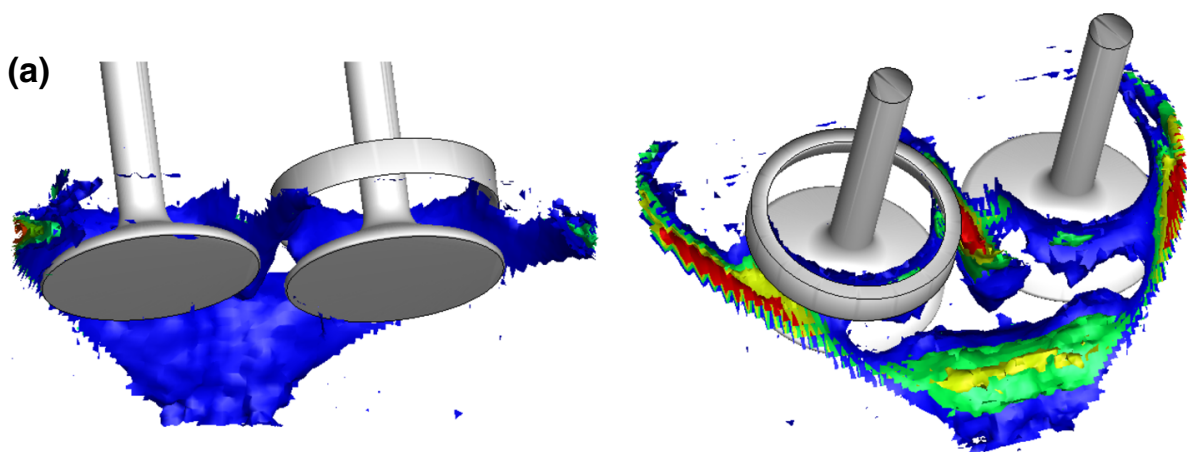

(b)

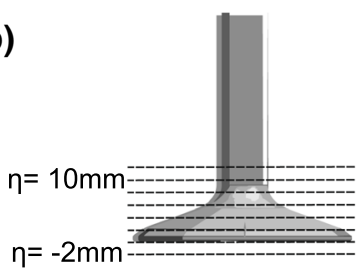

$\eta=-2 m m$
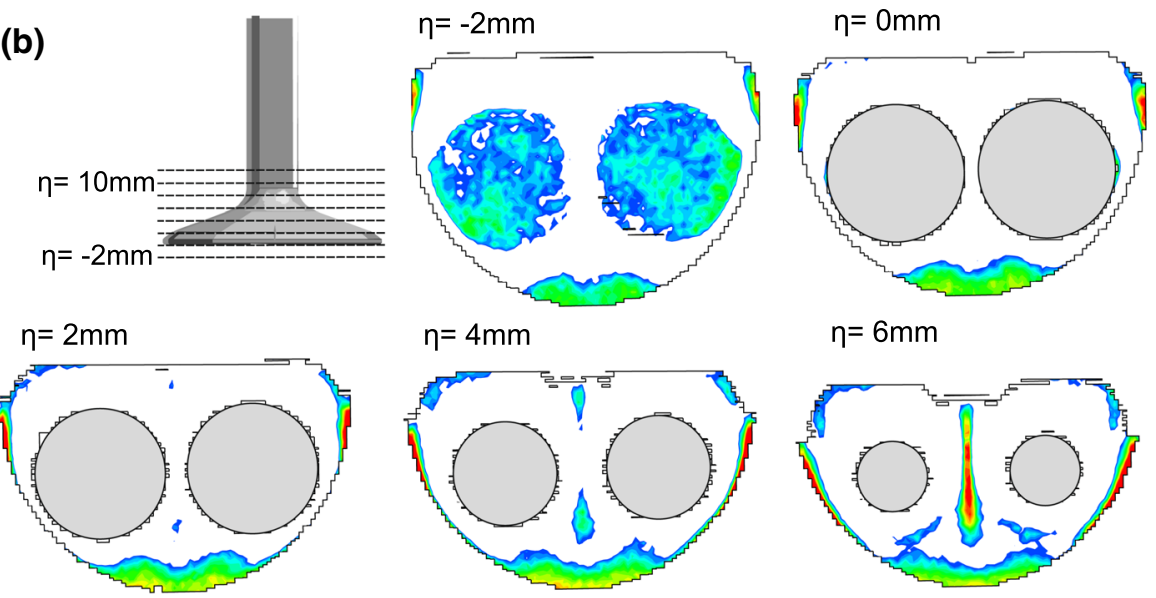

$\eta=4 \mathrm{~mm}$

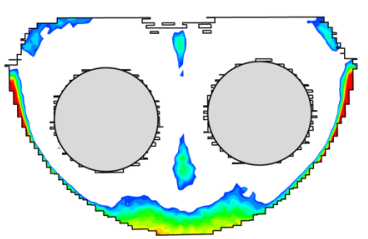

$\eta=6 \mathrm{~mm}$

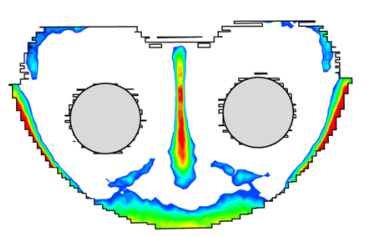

$\eta=10 \mathrm{~mm}$
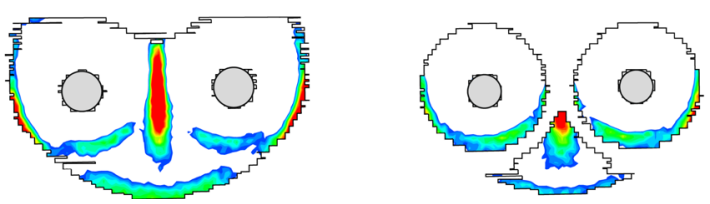

$\eta=12 \mathrm{~mm}$

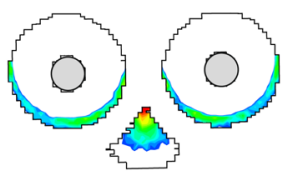

vel $\eta(\mathrm{m} / \mathrm{s}) \quad 0.000 .050 .100 .150 .200 .250 .300 .35$

heights until $\eta=8 \mathrm{~mm}$. In this region, the velocity of the recirculating flow reaches up to $33 \%$ of the mean inflow velocity inside the intake manifold (maximum velocity of recirculating mass flow: $\eta$-velocity $0.2 \mathrm{~m} / \mathrm{s}$; mean inflow velocity: $\eta$-velocity $\approx-0.6 \mathrm{~m} / \mathrm{s})$. At $6 \mathrm{~mm} \leq \eta \leq 12 \mathrm{~mm}$ a half-moon-shaped area of recirculating mass flow is present, situated inside the valve curtain. This recirculation zone has been identified in Sect. 4.2 regarding the flow distribution in the valve curtain. It covers $180^{\circ}$ of the valve circumference (see $\eta=10 \mathrm{~mm}$ ) but only occurs in the underflow region. The recirculating mass flow is extending upstream and entering the valve seat as can be identified in Fig. 12a with the pictured valve seat. A smaller, elongated area of recirculating mass flow evolves in the symmetry plane between both intake valves $(4 \mathrm{~mm} \leq \eta \leq 8 \mathrm{~mm})$. This recirculation zone is positioned just above the high-speed tumble plane created by the impinging annular flows of both intake channels. Smaller areas of recirculating mass flow are also visible near the cylinder wall for $0 \mathrm{~mm} \leq \eta \leq 8 \mathrm{~mm}$.

Figure 13 further quantifies the amounted area and volumetric flow associated with the recirculation zones identified on the $\eta$-slices presented in Fig. 12. Both the amounted area and volumetric flow are reported as percentage of the total cross-sectional area and total mass flow into the cylinder chamber $(66 \mathrm{~L} / \mathrm{min})$. Note that percentage values are reported for additional intermediate $\eta$ values that are not shown within Fig. 12. As $\eta$ increases in value (i.e., direction toward intake manifold), the flow recirculation area increases from 12 to $16 \%$. It is also noted, however, that the overall cross-sectional area of the $\eta$-slices decreases for $\eta>4 \mathrm{~mm}$. The percentage of recirculated mass flow shows a gradual increase from $4 \%$ at $\eta=0 \mathrm{~mm}$ to $7 \%$ at $\eta=7 \mathrm{~mm}$. Beyond $\eta=7 \mathrm{~mm}$, the percentage of 


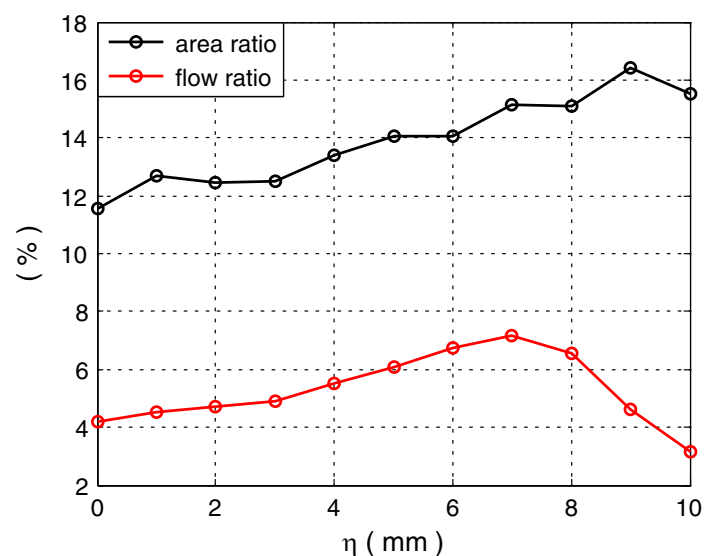

Fig. 13 Quantification of the recirculating volumetric flow inside the valve gap. Amounted area and recirculating volumetric flow as percentage of the total cross-sectional area and total volumetric flow into the cylinder chamber $(66 \mathrm{~L} / \mathrm{min})$

mass flow decreases to $3 \%$ at $\eta=10 \mathrm{~mm}$ where the recirculated flow is primarily only located within a small portion of the underflow region (see Fig. 12).

Although the amounted area and mass flow associated with the recirculation zones is small compared to the overall cross-sectional areas and flow into the engine, these recirculation zones can have large implications on charge filling and development of flow patterns within the engine. Charge filling, and volumetric efficiency, is reduced with larger recirculated flow areas and flow rates. Recirculation zones can also cause changes in flow patterns downstream within the cylinder chamber. Such effects could have larger implications on cyclic variability of the in-cylinder flow field, which is recognized as an important topic within SI engines (Heywood 1988; Voisine et al. 2011). Although the MRV measurements presented here are only capable of resolving the ensemble average volumetric flow field, the measurements are capable to experimentally resolve recirculation zones in 3D space within the inlet flow and are considered state-of-the-art. Identification of such zones can facilitate further experimental or numerical investigations that concentrate on resolving the instantaneous flow field in such regions to better understand charge filling and cyclic variation phenomena.

\subsection{Volumetric flow within intake manifold}

The volumetric flow is analyzed within the intake manifold to describe the annular flow as it approaches the inlet region near the valve head. Figure 14 shows contour slices of velocity magnitude at four cross section locations 1-4 within the Y-tube, dual-intake port manifold. The contour labeled 4 represents the cross section at the exit of the intake manifold and represents the flow past the imagined boundary of the intake manifold and cylinder chamber. Perpendicular views of each contour slice are individually shown on the right side of Fig. 14. In addition, an iso-surface representing the wake region downstream of the valve stem is shown in Fig. 14a. This iso-surface is identified as the volume with $\xi$-velocity $\leq-0.1 \mathrm{~m} / \mathrm{s}$. A negative $\xi$-velocity within the intake manifold is identified as a wake region with a reversed flow. Streamlines are added within Fig. 14a to further visualize the flow within the intake manifold and over the intake valves.

Figure 14 reveals that the flows within each intake manifold are strikingly symmetric. At location 1 , the flow resembles a homogeneous annular velocity distribution and is not individually shown on the right side of Fig. 14. At location 2, velocity increases toward the bottom of the contour slice where the flow accelerates due to the vastly approaching reduction in cross-sectional area and obstruction of the valve stem. The flow-on slice 3 shows the largest velocity magnitudes primarily along the bottom and outer side of the slice. The cross-sectional area at the bottom is the smallest due to the obstruction of the valve stem. The dual-intake ports (Y-tube) begin to merge toward the center cylinder axis and the velocity magnitude is higher on the outer sides of the slices than on the inner sides where the slices from each valve face each other. High velocity magnitudes are also shown to travel around the valve stem, but a recirculation zone is located directly behind the valve stem. This recirculation zone exhibits moderate velocity magnitudes (up to $1.3 \mathrm{~m} / \mathrm{s}$ ) which contain a negative $\xi$-velocity component ( $\xi$-velocity as low as $-0.3 \mathrm{~m} / \mathrm{s}$ although values are not explicitly shown). The velocity on slice 4 can be classified as the overflow and the underflow as discussed in Sect. 4.1. At location 4, the velocity magnitude is largest in the overflow region where the high velocity magnitude from slice 3 is primarily directed. The underflow region exhibits a small ring-like region of high velocities $(1.5 \mathrm{~m} / \mathrm{s})$ entering the cylinder, but primarily shows a large region of velocities less than $1 \mathrm{~m} / \mathrm{s}$. This low velocity region primarily consists of the recirculated flow that is re-entering the intake manifold and can be seen more clearly from the recirculated flow iso-surfaces shown in Fig. 12. A recirculation zone is also shown to exist behind the valve stem and exhibit velocities of $1.2 \mathrm{~m} /$ $\mathrm{s}$ or lower. The velocity magnitudes of the MRV measurements can be calculated back to the real-engine flow velocity using the scaling factor $(S F)$.

\section{Potential of MRV for engine flow analysis}

The MRV technique presented in this work can be seen as a new approach to investigate average 3D flow topology 
Fig. 14 Contour slices of velocity magnitude at four cross section locations 1-4 within the Y-tube. a Streamlines visualize the flow through the valve gap. A zone of recirculating mass flow can be identified just downstream of the valve stem $(\xi$-velocity $\leq-0.1 \mathrm{~m} / \mathrm{s})$. The positions of the four cross section locations are marked and visualized from a different perspective (b). Perpendicular views of each contour slice are individually shown on the right side (c). The velocity magnitude can be scaled to real-engine velocity using the $S F$

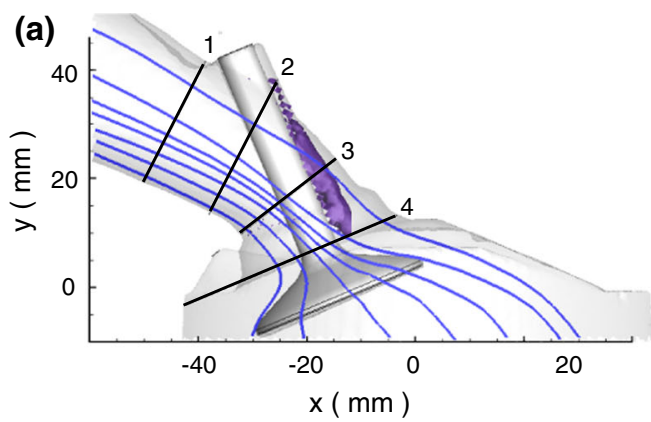

(b)

(c)

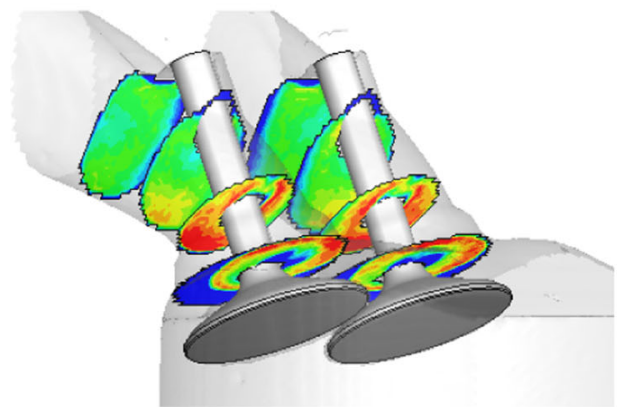

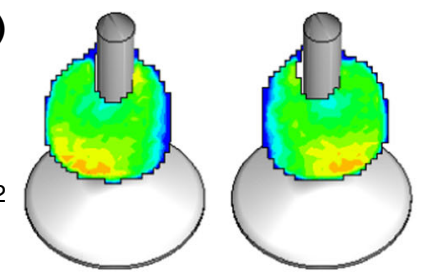

3

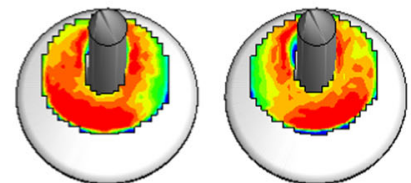

4
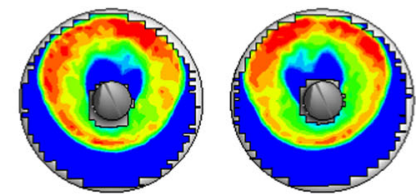

$|\bar{V}|(\mathrm{m} / \mathrm{s}): \quad 1 \quad 1.11 .21 .31 .41 .5$

$\operatorname{vel} \xi(\mathrm{m} / \mathrm{s}): \leq-0.1$ within the entire measurement domain. It is anticipated that MRV is suitable to experimentally resolve differences in the inlet flow due to geometrical changes of the intake manifold or engine geometry. This is a primary focus for future experiments, such that volumetric flow topologies can be studied in a fast and cost-efficient way. The model generation by Polyamide rapid prototyping allows easy variations and the MR scanner low acquisition time and automated post-processing. Recent developments of MRV have provided the ability for 4D flow imaging (Wassermann et al. 2012). By realizing valve movement and flow rate modulations, the transient behavior of the intake flow could be analyzed. This can be potentially used to investigate the dynamic development of the intake flow during a period during the induction stroke. MRV has also been utilized with gaseous working fluids (e.g., hyperpolarized ${ }^{3} \mathrm{He}$ (Rochefort et al. 2007)). Such capability would provide the opportunity to work with higher flow rates (e.g., to simulate higher RPMs) for which the flow may become compressible. All aforementioned aspects, as well as the presented data, are ideal to provide an improved understanding of engine flows as well as develop IC engine simulations. Although MRV is restricted to phase-averaged flow velocities, its capabilities and further potential make it an attractable technique for engine flow bench testing.

\section{Conclusions}

In this study, MRV measurements were utilized to investigate the volumetric intake flow for an internal combustion engine geometry. Measurements were performed in a 1:1 scale Polyamide model of a single-cylinder direct-injection spark-ignition optical engine under steady flow conditions. The valve position was fixed matching the engine geometry during intake similar to flow bench experiments. The flow medium utilized was de-ionized water with a Gadoliniumbased contrast agent. MRV measurements were compared with PIV measurements performed for the matching geometry (i.e., corresponding crank-angle degree) within the operated optical engine (800 RPM) for validation. Differences of the operating parameters between MRV and PIV were well addressed. Velocity component profiles along several vertical and horizontal positions within the central tumble plane show excellent agreement until $20 \mathrm{~mm}$ below the pentroof where the flow deviates from the engine flow due to the absence of the piston boundary. It is assumed that agreement of the in-cylinder flow within the central tumble plane implies similar velocity distributions within the inlet system and the overall flow structure inside the cylinder chamber.

MRV measurements were analyzed with the mid-valve tumble plane, cross-tumble plane, and swirl plane to describe the volumetric flow of the inlet flow entering the cylinder chamber. Flow features such as the annular jet-like flows extending into the cylinder, their influence on largescale in-cylinder flow motion, as well as recirculation zones where the flow is redirected back into the intake manifold were identified in 3D space. The inlet flow through the valve curtain was analyzed to quantify velocities and mass flow rates entering the cylinder chamber around the entire valve curtain perimeter. Radial velocities 
and flow rates were largest within the overflow region, while a large recirculated flow region within the underflow region significantly reduces local mass flow entering the cylinder chamber up to $50 \%$. These recirculation zones can have large implications on cylinder charge filling and could attribute to variations in the in-cylinder flow for individual engine cycles. The recirculation zones within the entire cylinder and intake manifold were identified in 3D space. The majority of mass flow recirculation occurs in the underflow region between the valve curtain and cylinder wall where it is attached. Flow recirculation occurs further along the periphery of the valve curtain and extends up to $180^{\circ}$ of the valve circumference. A recirculation zone was also identified within the intake manifold downstream of the valve stems. The flow within each intake manifold is strikingly symmetric. Contour slices of velocity magnitude describe how the flow accelerates within the manifold due to reduced cross-sectional areas. The flow follows the geometry of the intake manifold and most of the flow was shown to discharge into the cylinder as overflow.

MRV measurements performed within this work reveal the ability to investigate the volumetric flow within the intake manifold and the cylinder chamber. Although MRV measurements presented only provide ensemble mean flow velocities, the ability to experimentally resolve the volumetric flow within the intake manifold and cylinder chamber is considered state-of-theart. This can be seen as a large improvement with regards to conventional steady flow experiments, which are not traditionally capable of quantifying spatially resolved flow details within the entire volume domain. MRV can be used to experimentally investigate flow sensitivities to geometrical changes of the engine. Future MRV investigations for engine research will measure the volumetric flows for different valve lifts as well as moving valves. Overall the presented measurements can lead to a fast and comprehensive analysis of the IC engine induction as well as provide useful velocity information for the validation of simulation tools.

Acknowledgments Financial support by Deutsche Forschungsgemeinschaft (DFG) through PE 2068 and EXC 259 is gratefully acknowledged. The authors are also especially thankful to Prof. A. Dreizler for fruitful discussions.

\section{References}

Baum E, Peterson B, Böhm B, Dreizler A (2014) On the validation of LES applied to internal combustion engine flows: part 1: comprehensive experimental database. Flow Turbul Combust 92:269-299

Baum E, Peterson B, Surmann C, Michaelis D, Böhm B, Dreizler A (2013) Investigation of the 3D flow field in an IC engine using tomographic PIV. Proc Combust Inst 34(2):2903-2910
Bensler H, Freek C, Beesten B, Ritter A, Hentschel AW (1998) An experimental and numerical study of the steady-state flow of a SI-engine intake port. SAE Technical Paper 982470

Benson MJ, Elkins CJ, Mobley PD, Alley MT, Eaton JK (2010) Three-dimensional concentration field measurements in a mixing layer using magnetic resonance imaging. Exp Fluids 49(1):43-55

Bicen AF, Vafidis C, Whitelaw JH (1985) Steady and unsteady airflow through the intake valve of a reciprocating engine. J Fluids Eng 107(3):413-420

Boesiger P, Maler S (1992) Visualization and quantification of the human blood flow by magnetic resonance imaging. J Biomech 25(1):55-67

Chen A, Lee KC, Yianneskis M (1995) Velocity characteristics of steady flow through a straight generic inlet port. J Numer Methods Fluids 21(7):571-590

de Rochefort L, Vial L, Fodil R, Maître X, Louis B, Isabey D, Caillibotte G, Thiriet M, Bittoun J, Durand E, Sbirlea-Apiou G (2007) In vitro validation of computational fluid dynamic simulation in human proximal airways with hyperpolarized ${ }^{3} \mathrm{He}$ magnetic resonance phase-contrast velocimetry. J Appl Physiol 102:2012-2023

Cheung RSW, Nadarajah S, Tindal MJ, Yianneskis M (1990) An experimental study of velocity and Reynolds stress distributions in a production engine inlet port under steady flow conditions. SAE Technical Paper 900058

Dittmeyer R, Tropea C (1990) LDA measurements of diesel engine inlet flows in a stationary flow rig. In: Fifth international symposium on applications of LDA to fluid mechanics, Lisbon, Portugal

El Tahry SH, Khalighi B, Kuziak WR (1987) Unsteady-flow velocity measurements around an intake valve of a reciprocating engine. SAE Technical Paper 870593

Elkins CJ, Alley MT (2007) Magnetic resonance velocimetry: applications of magnetic resonance imaging in the measurement of fluid motion. Exp Fluids 43(6):823-858

Elkins CJ, Markl M, Iyengar A, Wicker R, Eaton JK (2004) Full-field velocity and temperature measurements using magnetic resonance imaging in turbulent complex internal flows. Int $\mathrm{J}$ Heat Fluid Flow 25(5):702-710

Elkins CJ, Alley MT, Saetran L, Eaton JK (2008) Three-dimensional magnetic resonance velocimetry measurements of turbulence quantities in complex flow. Exp Fluids 46(2):285-296

Fajardo C, Sick V (2009) Kinetic energy and dissipation rate spectra of high- and low-swirl internal combustion engine flows. SAE Technical Paper 01-0651

Fan L, Reitz RD, Trigui N (1999) Intake flow simulation and comparison with PTV measurements. SAE Technical Paper 01-0176

Fitzgeorge D, Allison JL (1962) Air swirl in a road-vehicle diesel engine. Proc Inst Mech Eng Automob Div 16:151-177

Fukutani I, Watanabe E (1982) Air flow through poppet inlet valvesanalysis of static and dynamic flow coefficients. SAE Technical Paper 820154

Grundmann S, Wassermann F, Lorenz R, Jung B, Tropea C (2012) Experimental investigation of helical structures in swirling flows. Int J Heat Fluid Flow 37(1):51-63

Haacke M, Brown R, Thompson M, Venkatesan R (1999) Magnetic resonance imaging. Wiley-Liss, New York

Heim DM, Ghandhi JB (2011) Investigation of swirl meter performance. Proc Inst Mech Eng D J Automob Eng 225:1067-1077

Heywood JB (1988) Internal combustion engine fundamentals. McGraw-Hill, New York

Hill PG, Zhang D (1994) The effects of swirl and tumble on combustion in spark-ignition engines. Prog Energy Combust Sci 20(5):373-429 
Justham T, Jarvis S, Clarke A, Garner CP, Hargrave GK, Halliwell NA (2006) Simultaneous study of intake and in-cylinder IC engine flow fields to provide an insight into intake induced cyclic variations. J Phys 45(1):146-153

Khalighi B, El Tahry SH, Kuziak WR (1986) Measured steady flow velocity distributions around a valve/seat annulus. SAE Technical Paper 860462

Mahmood Z, Chen A, Yianneskis M, Ganti G (1996) On the structure of steady flow through dual-intake engine ports. J Numer Methods Fluids 23(10):1085-1109

Nadarajah S, Balabani S, Tindal MJ, Yianneskis M (1998) The turbulence structure of the annular non-swirling flow past an axisymmetric poppet valve. Proc Inst Mech Eng 212(6):455-471

O'Donnell M (1985) NMR blood flow imaging using multiecho, phase contrast sequences. Med Phys 12:59-64

Pajković VR, Petrović SV (2008) Spatial flow velocity distribution around an inlet port/valve annulus. Thermal Sci 12(1):73-83
Tabaczynski RJ (1976) Turbulence and turbulent combustion in spark-ignition engines. Prog Energy Combust Sci 2(3):143-165

Tindal MJ, Cheung RSW, Yianneskis M (1988) Velocity characteristics of steady flows through engine inlet ports and cylinders. SAE Technical Paper 880383

Voisine M, Thomas L, Borée J (2011) Spatio-temporal structure and cycle to cycle variations of an in-cylinder tumbling flow. Exp Fluids 50(5):1393-1407

Wassermann F, Hecker D, Jung B, Markl M, Seifer A, Grundmann S (2012) Phase-locked 3D3C measurements in a bistable fluidic oscillator. Exp Fluids 54(3):1-15

Westerweel J (1994) Efficient detection of spurious vectors in particle image velocimetry data. Exp Fluids 16(3-4):236-247 